\title{
Synthesis and Biological Evaluation of the Southern Hemisphere of Spirastrellolide A and Analogues
}

\author{
Jagadeesh Nagendra Manda, Barry B. Butler Jr, and Aaron Aponick* \\ *aponick@chem.ufl.edu
}

Florida Center for Heterocyclic Compounds and Department of Chemistry, University of Florida Gainesville, Florida 32611, United States.

\section{Supporting information}

Table of Contents:

\begin{tabular}{|c|c|c|}
\hline & ${ }^{1} \mathrm{H}$ NMR and ${ }^{13} \mathrm{C}$ NMR spectra & page no \\
\hline 1 & Compound 18 & $\mathrm{~S} 2$ \\
\hline 2 & Compound 19 & S3 \\
\hline 3 & Compound 20 & $\mathrm{~S} 4$ \\
\hline 4 & Compound 11 (step 1) & S5 \\
\hline 5 & Compound 11 & S6 \\
\hline 6 & Compound 21 & S7 \\
\hline 7 & Compound 22 & $\mathrm{~S} 8$ \\
\hline 8 & Compound 5 & S9 \\
\hline 9 & Compound 25 & S10 \\
\hline 10 & Compound 6 & S11 \\
\hline 11 & Compound 26 & S12 \\
\hline 12 & Compound 4 & S13 \\
\hline 13 & Compound 29 & S14 \\
\hline 14 & Compound $\mathbf{3 0}$ & S15 \\
\hline 15 & Mosher's ester analysis & S16 \\
\hline 16 & Compound 34 & S19 \\
\hline 17 & Relative stereochemistry of C20-C23 diol & $\mathrm{S} 20$ \\
\hline 18 & Compound $\mathbf{3}$ & $\mathrm{S} 24$ \\
\hline 19 & Compound 35 & $\mathrm{~S} 25$ \\
\hline 20 & Compound 37 & $\mathrm{~S} 26$ \\
\hline 21 & Compound 38 & S27 \\
\hline 22 & Compound 39 & S27 \\
\hline 23 & Compound $\mathbf{4 0}$ & S29 \\
\hline 24 & Compound 41 (step 1) & $\mathrm{S} 30$ \\
\hline 25 & Compound 41 & S31 \\
\hline 26 & Compound 42 & $\mathrm{~S} 32$ \\
\hline 27 & Compound 43 & S33 \\
\hline 28 & PP2A enzyme assay studies & S34 \\
\hline
\end{tabular}




\section{NMR data}

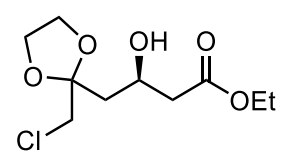

Compound $18-{ }^{1} \mathrm{H}$ NMR $\left(500 \mathrm{MHz}, \mathrm{CDCl}_{3}\right)$
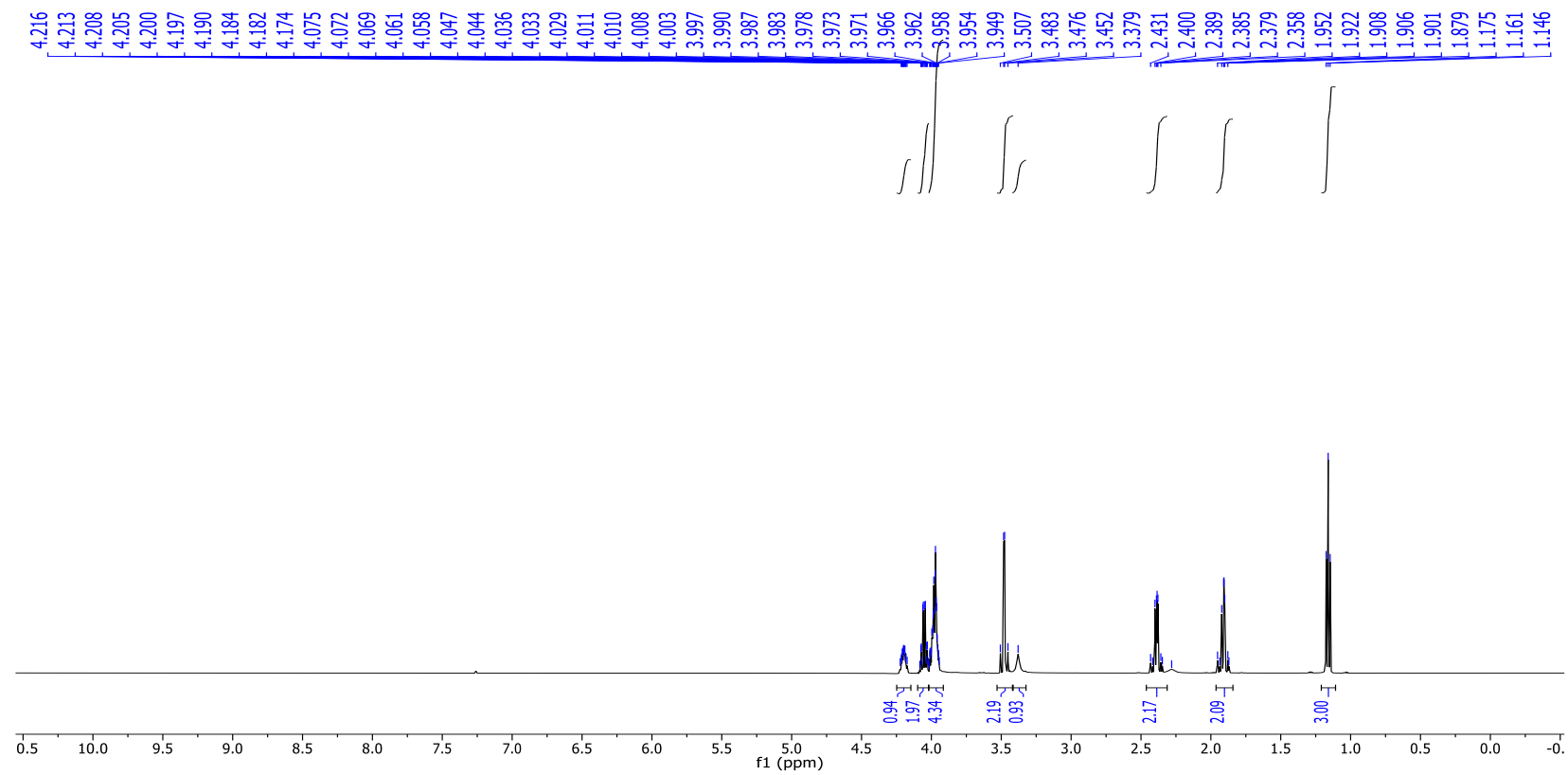

Compound $18-{ }^{13} \mathrm{C}$ NMR $\left(125 \mathrm{MHz}, \mathrm{CDCl}_{3}\right)$

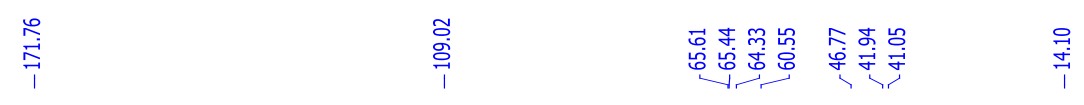

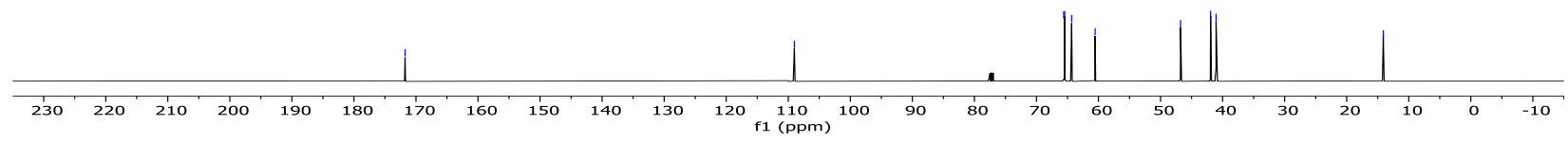


(O)

Compound $19-{ }^{1} \mathrm{H}$ NMR $\left(500 \mathrm{MHz}, \mathrm{CDCl}_{3}\right)$

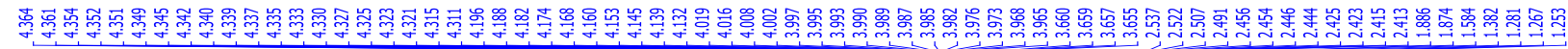

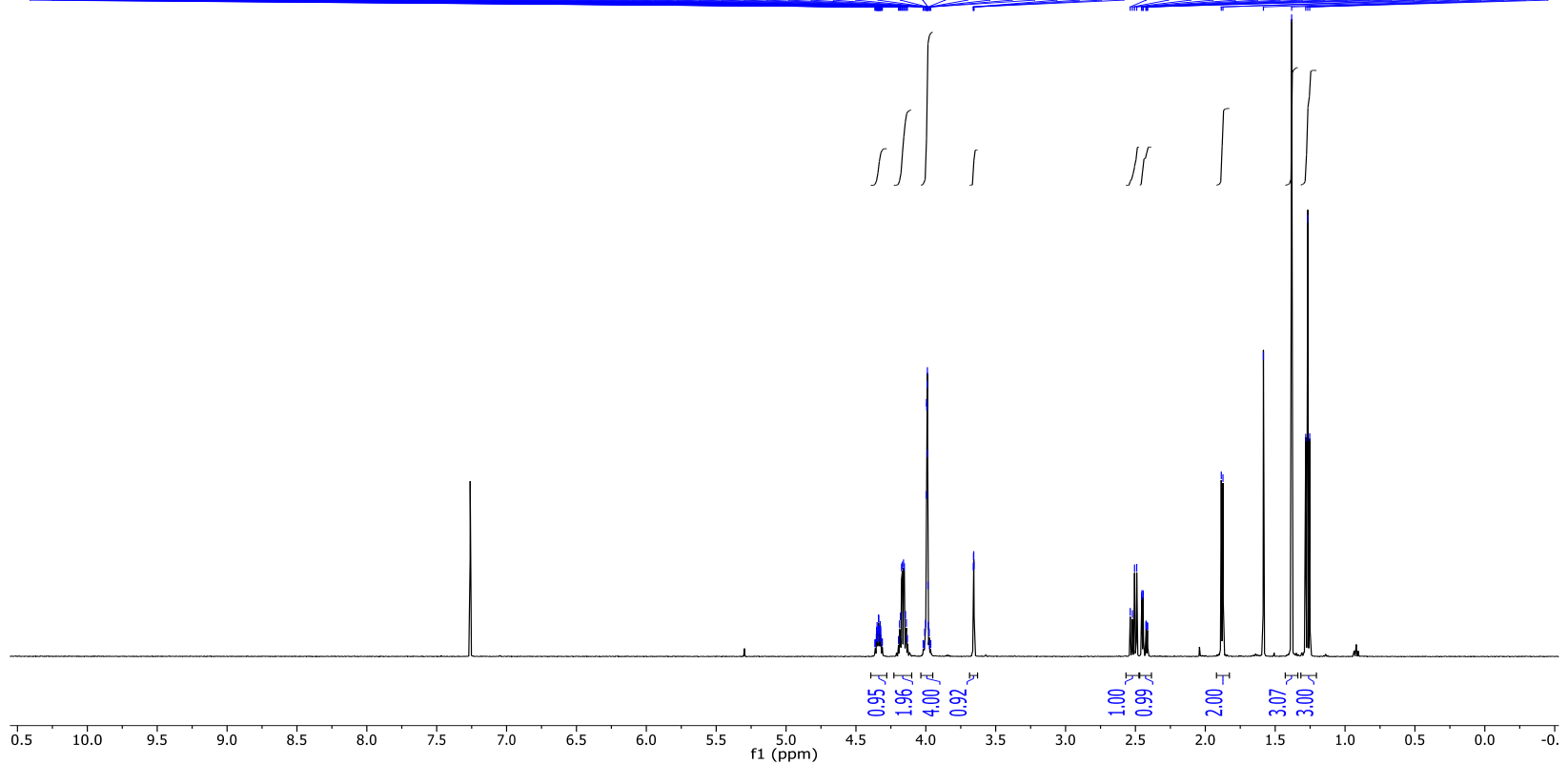

Compound $19-{ }^{13} \mathrm{C}$ NMR $\left(150 \mathrm{MHz}, \mathrm{CDCl}_{3}\right)$

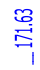

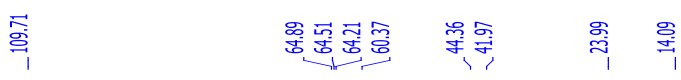

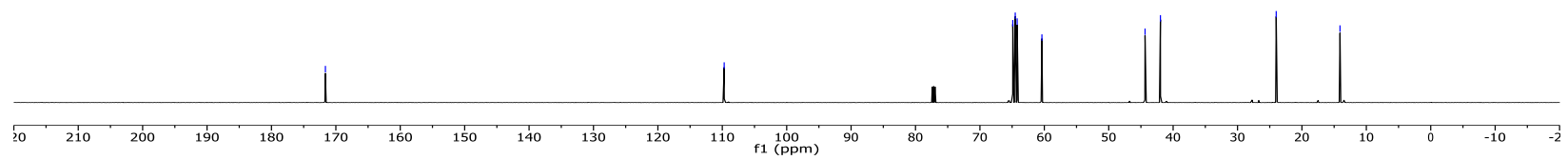

Compound 19 - HPLC chromatogram
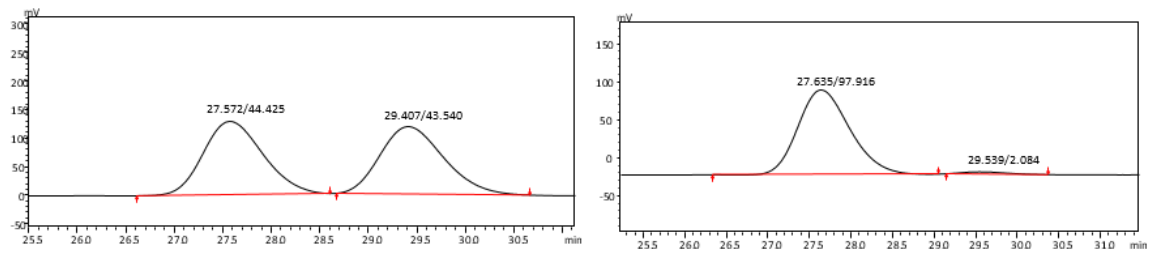


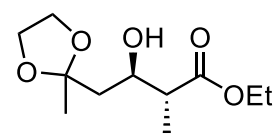

Compound $20-{ }^{1} \mathrm{H}$ NMR $\left(500 \mathrm{MHz}, \mathrm{CDCl}_{3}\right)$

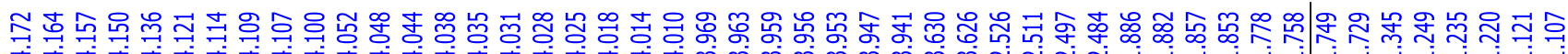

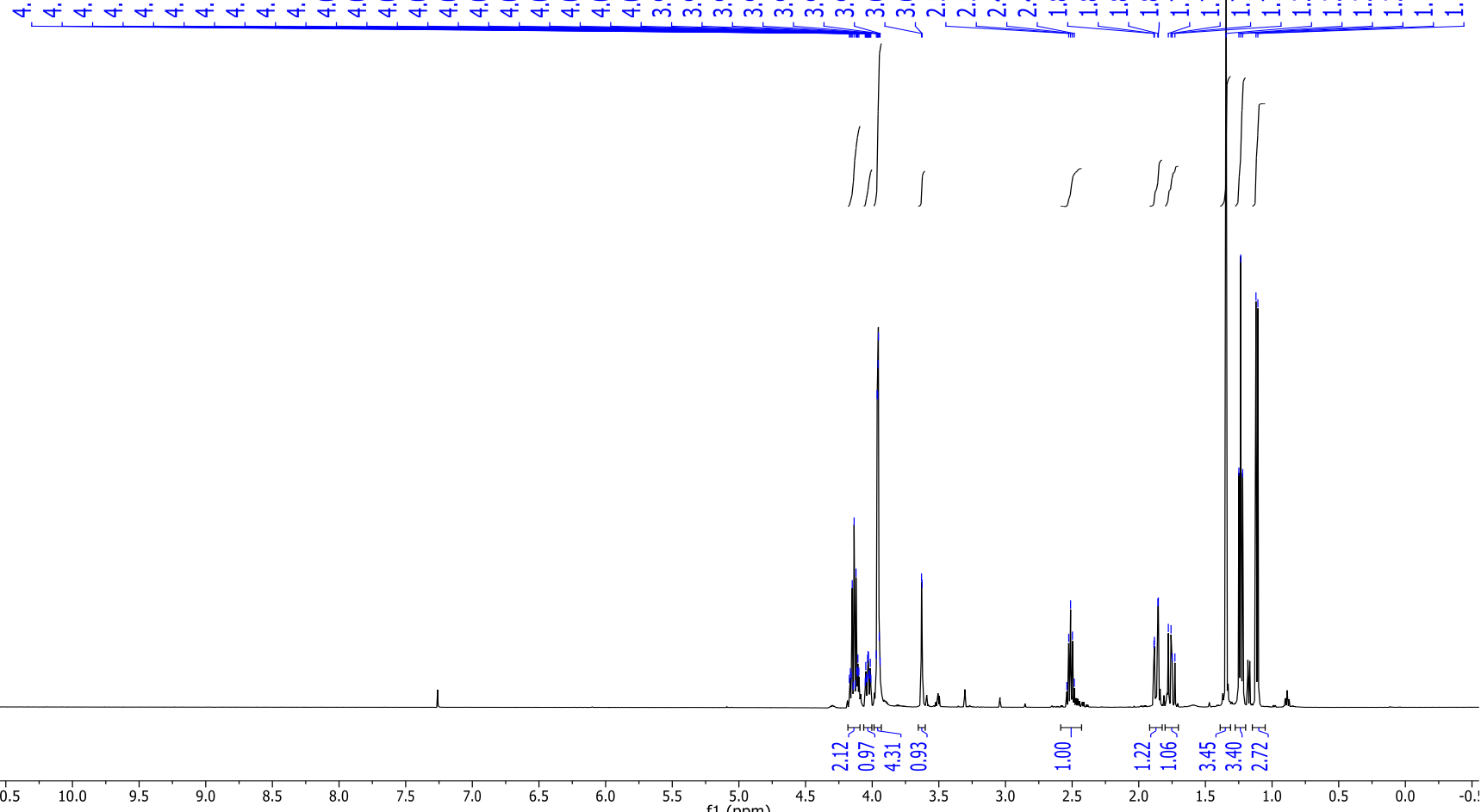

Compound $20-{ }^{13} \mathrm{C}$ NMR $\left(125 \mathrm{MHz}, \mathrm{CDCl}_{3}\right)$

\begin{tabular}{|c|c|c|}
\hline \multicolumn{2}{|r|}{ 苛 } & \\
\hline
\end{tabular}

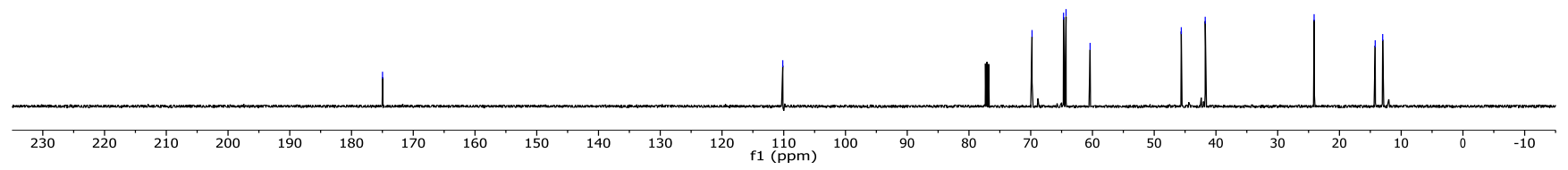




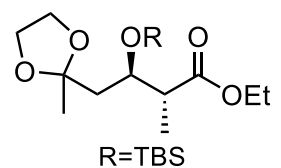

Compound 11 (step 1) - ${ }^{1} \mathrm{H}$ NMR $\left(500 \mathrm{MHz}, \mathrm{CDCl}_{3}\right)$

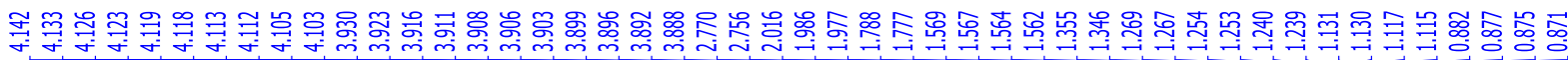

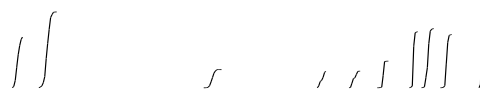

Wh
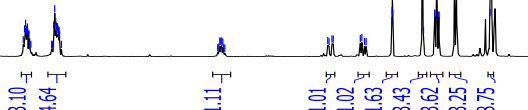

Compound 11 (step 1) $-{ }^{13} \mathrm{C}$ NMR $\left(125 \mathrm{MHz}, \mathrm{CDCl}_{3}\right)$
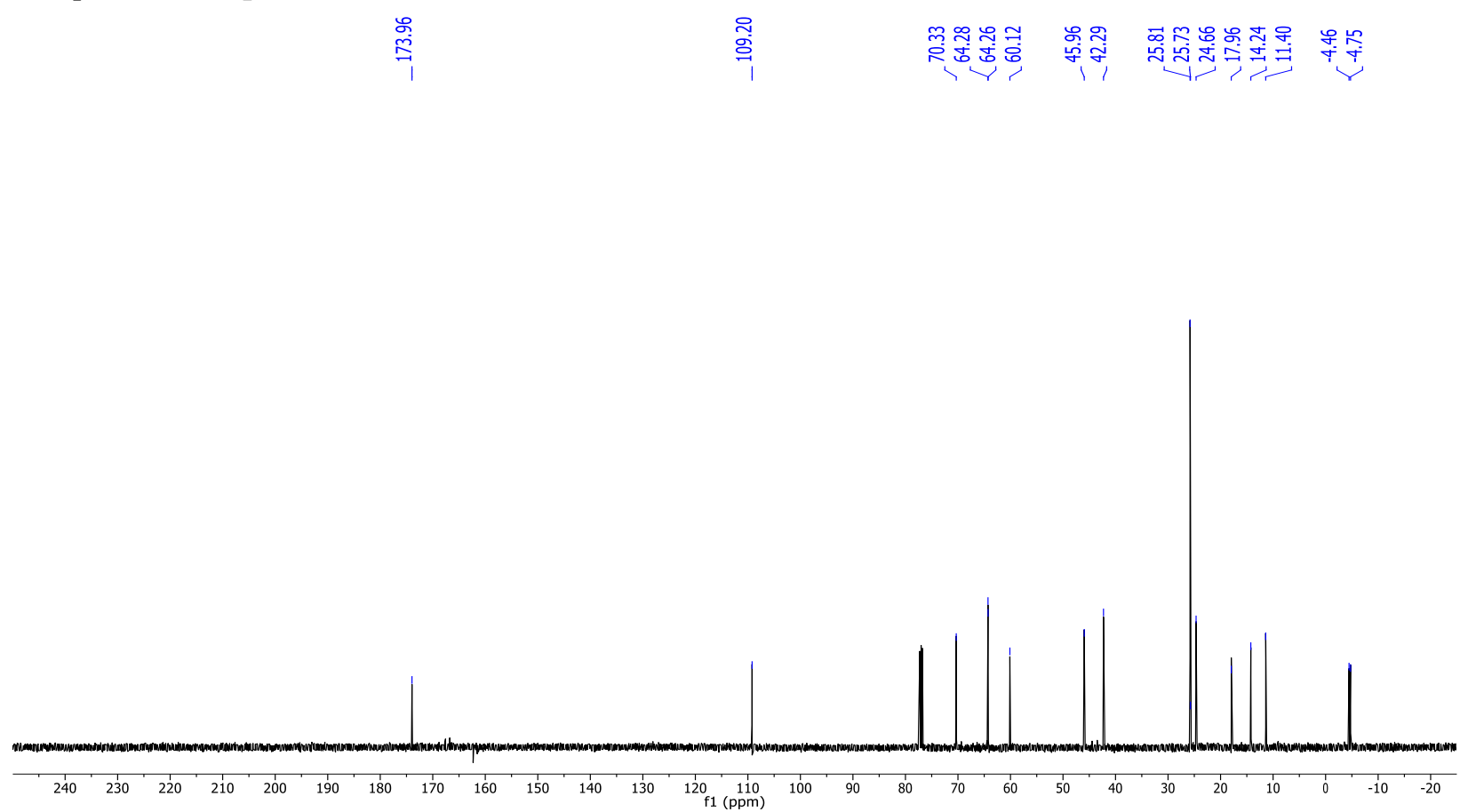


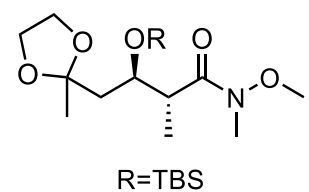

Compound $11-{ }^{1} \mathrm{H}$ NMR $\left(500 \mathrm{MHz}, \mathrm{CDCl}_{3}\right)$

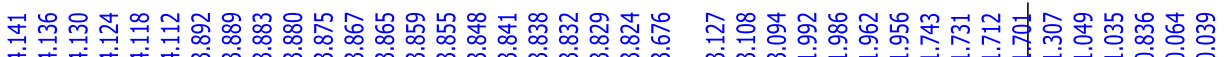

-1

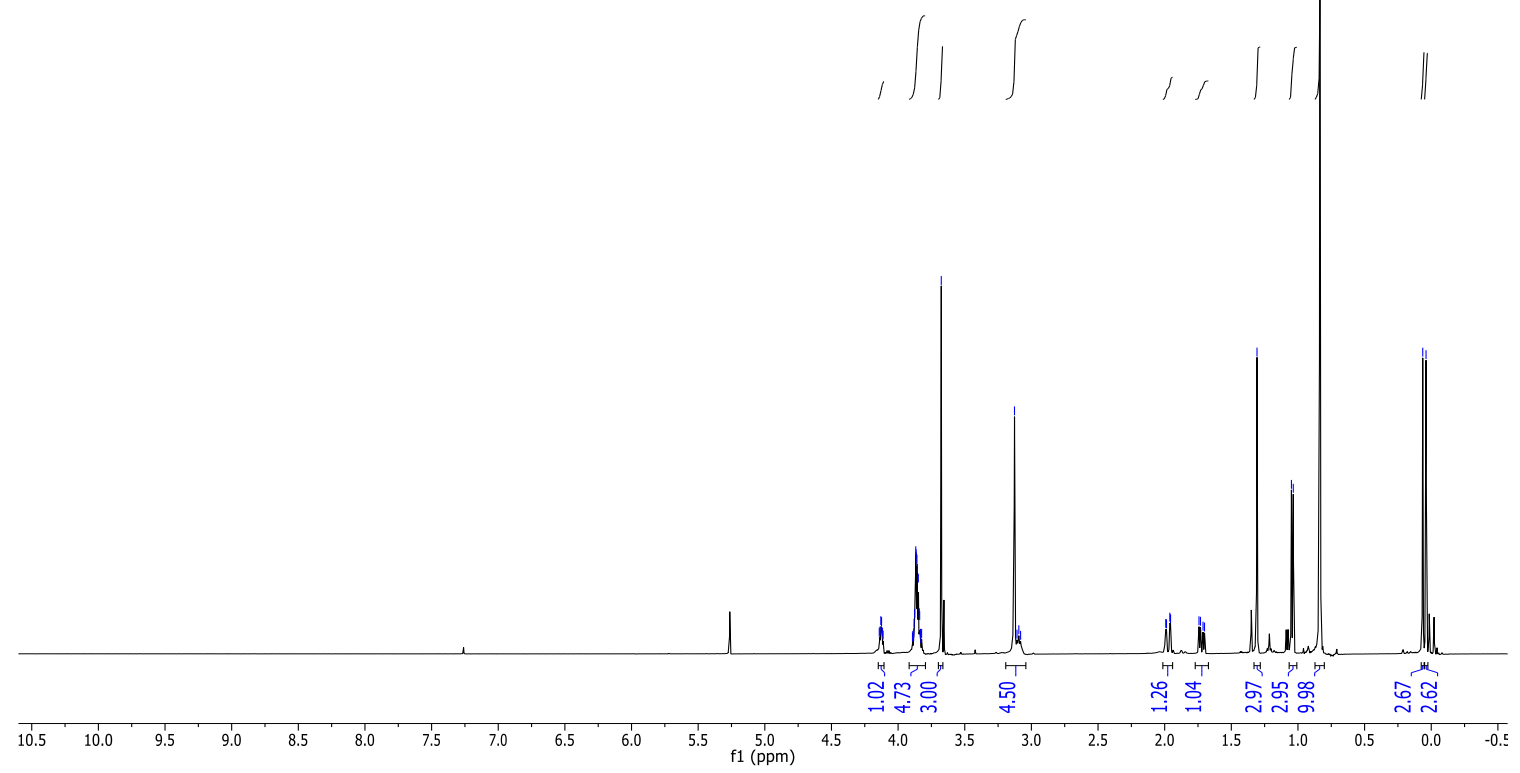

Compound $11-{ }^{13} \mathrm{C}$ NMR $\left(125 \mathrm{MHz}, \mathrm{CDCl}_{3}\right)$
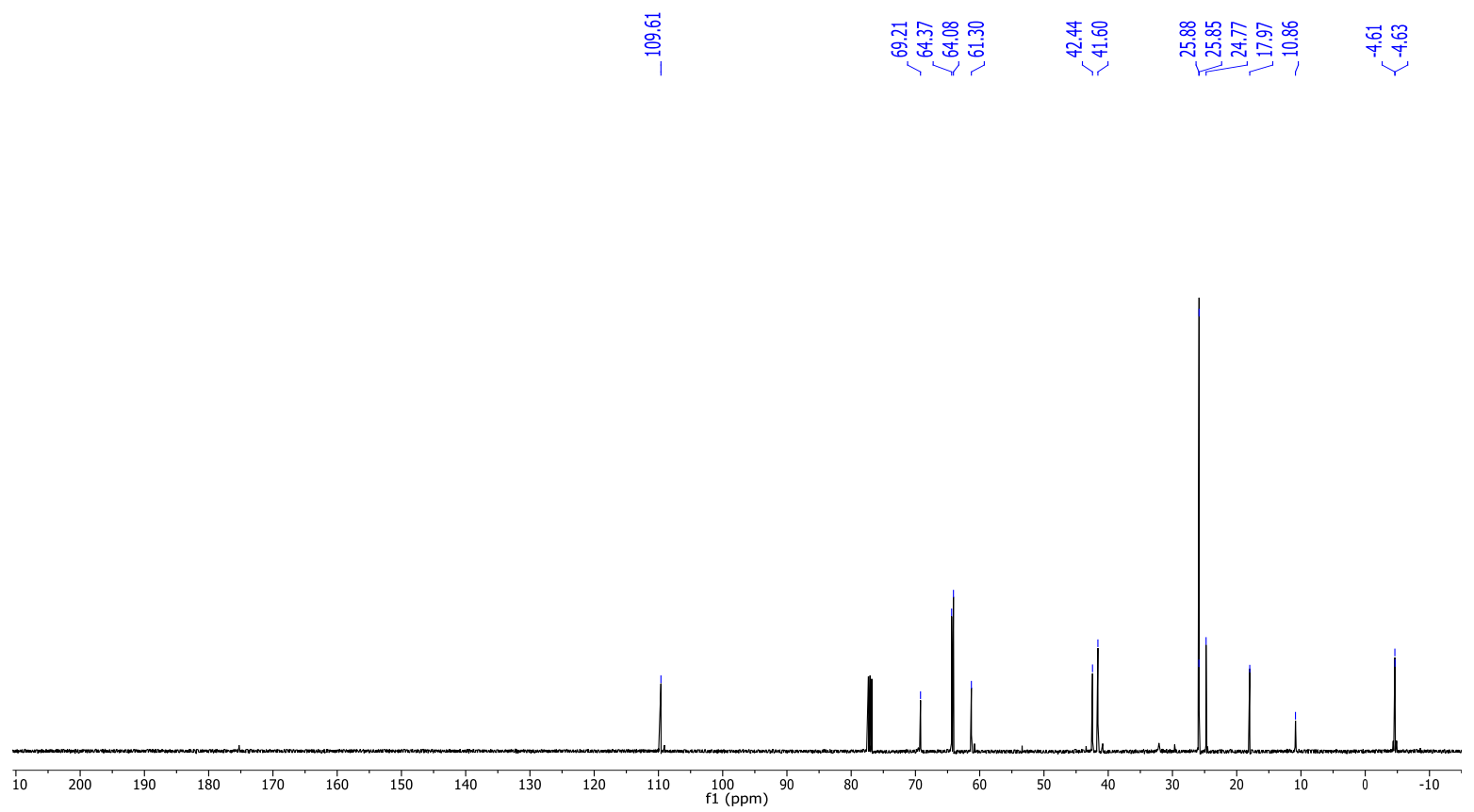


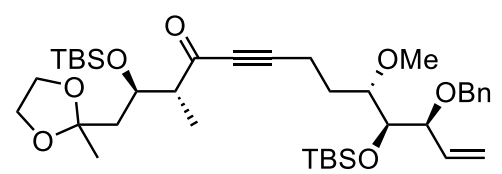

Compound $21-{ }^{1} \mathrm{H}$ NMR $\left(500 \mathrm{MHz}, \mathrm{CDCl}_{3}\right)$

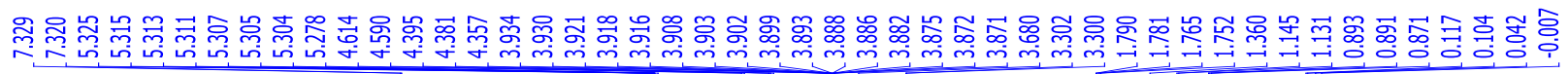

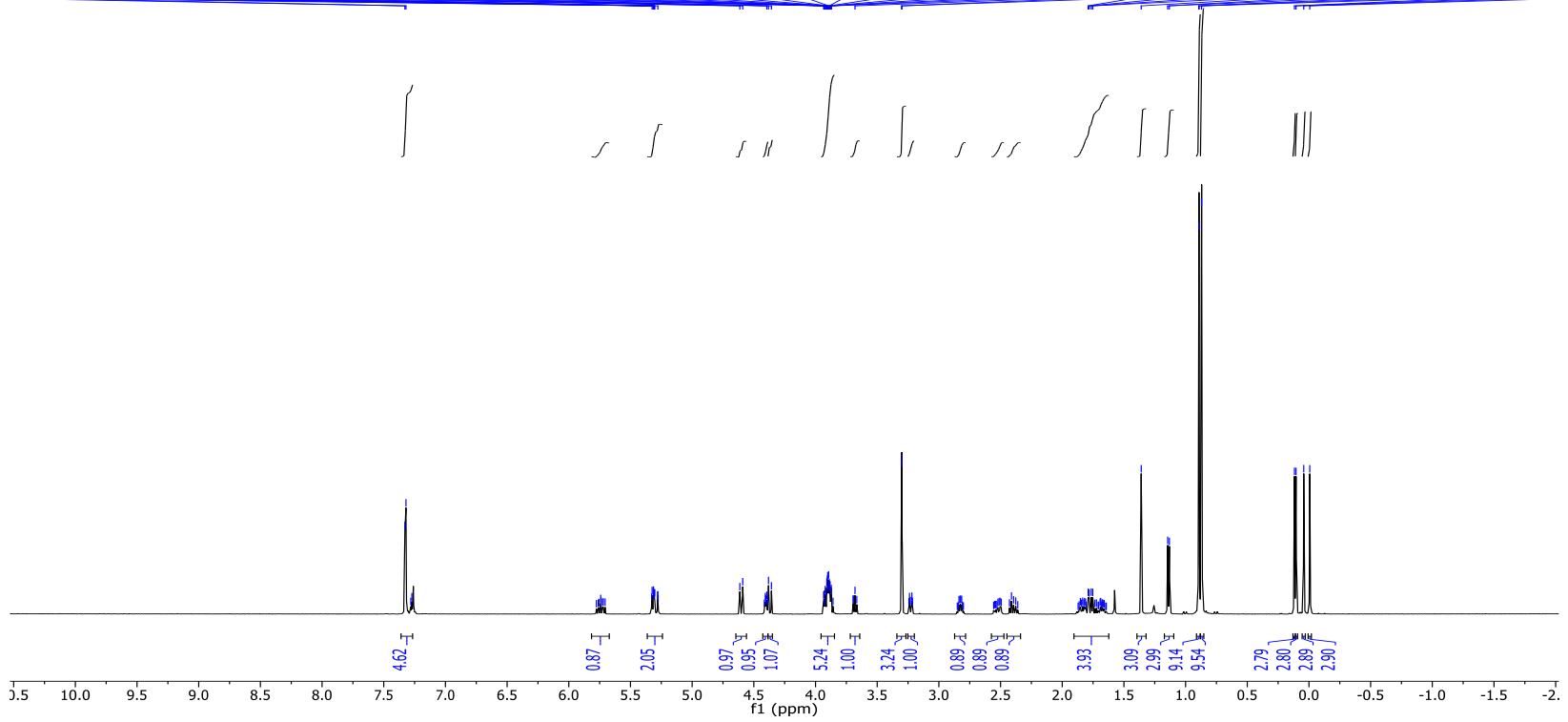

Compound $21-{ }^{13} \mathrm{C}$ NMR $\left(125 \mathrm{MHz}, \mathrm{CDCl}_{3}\right)$

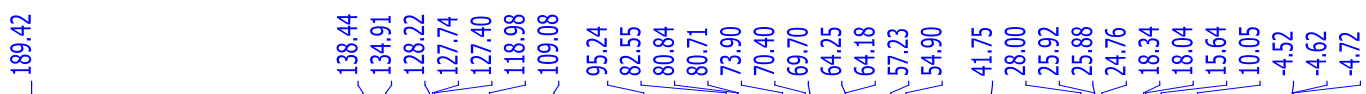

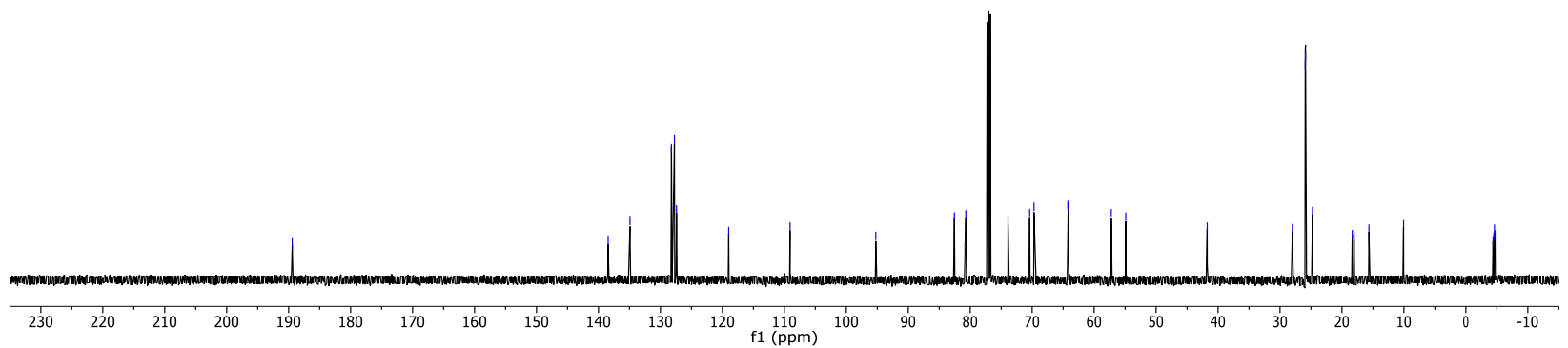




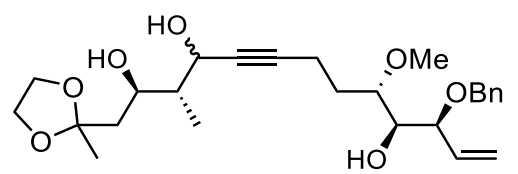

Compound $22-{ }^{1} \mathrm{H}$ NMR $\left(500 \mathrm{MHz}, \mathrm{CDCl}_{3}\right)$

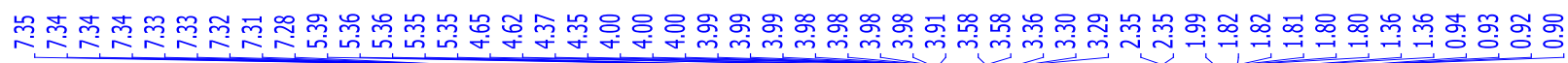

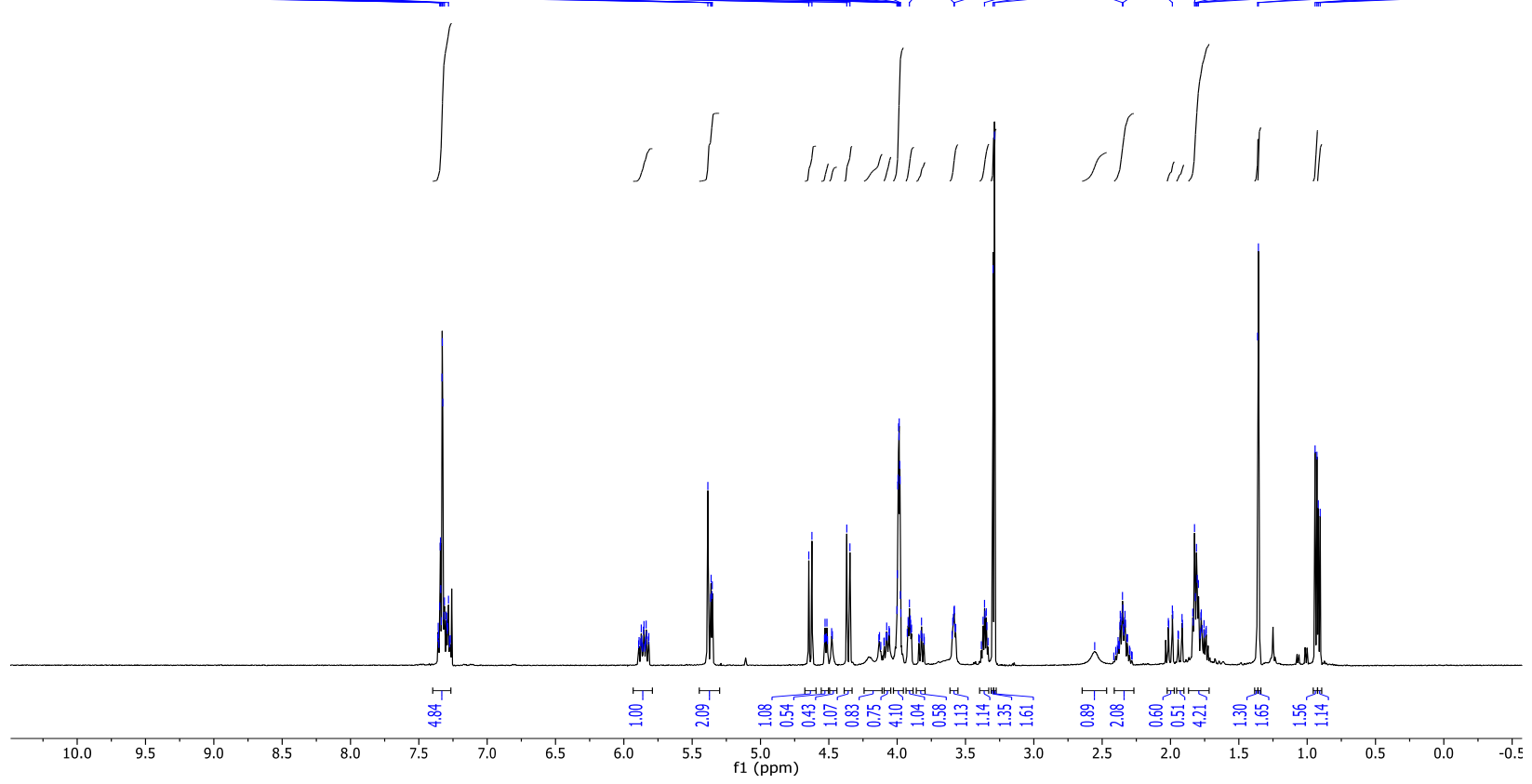

Compound $22-{ }^{13} \mathrm{C}$ NMR ( $\left.125 \mathrm{MHz}, \mathrm{CDCl}_{3}\right)$

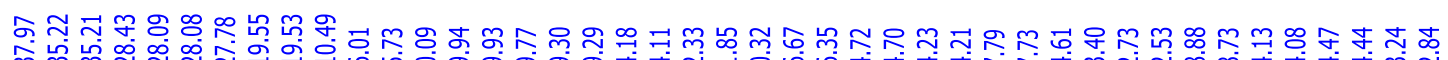

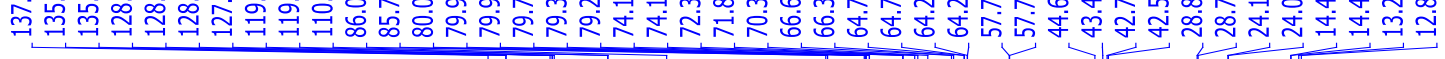

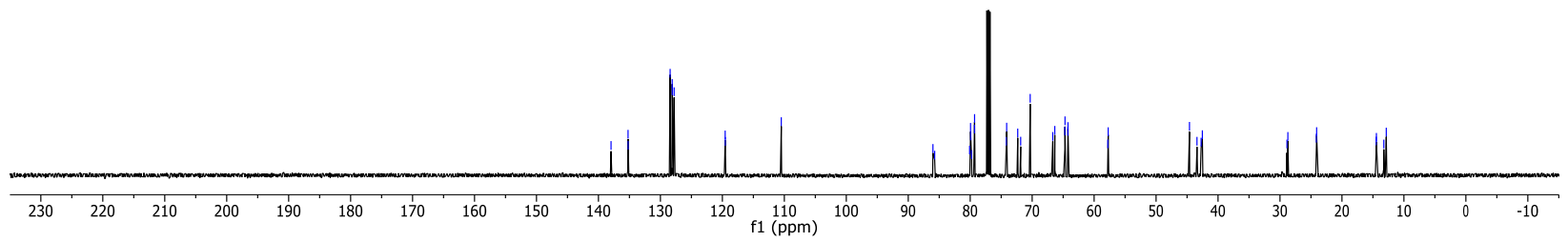




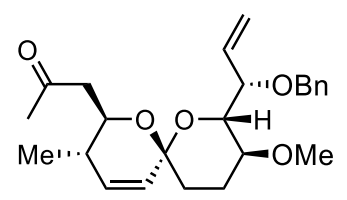

Compound $5-{ }^{1} \mathrm{H}$ NMR $\left(500 \mathrm{MHz}, \mathrm{CDCl}_{3}\right)$

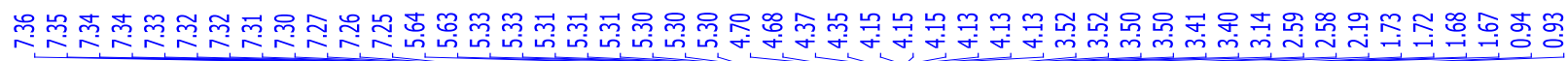

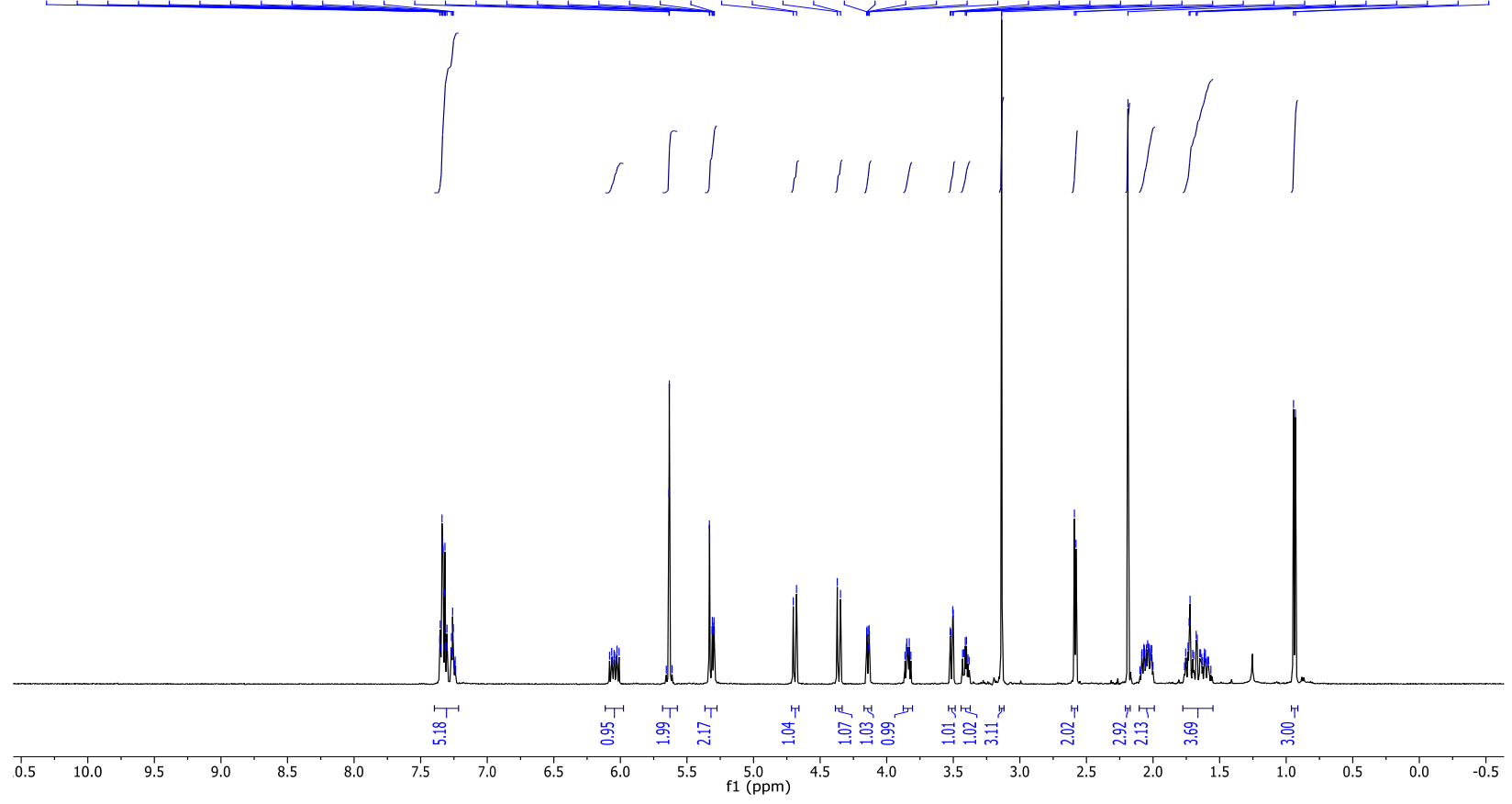

Compound $5-{ }^{13} \mathrm{C}$ NMR $\left(125 \mathrm{MHz}, \mathrm{CDCl}_{3}\right)$
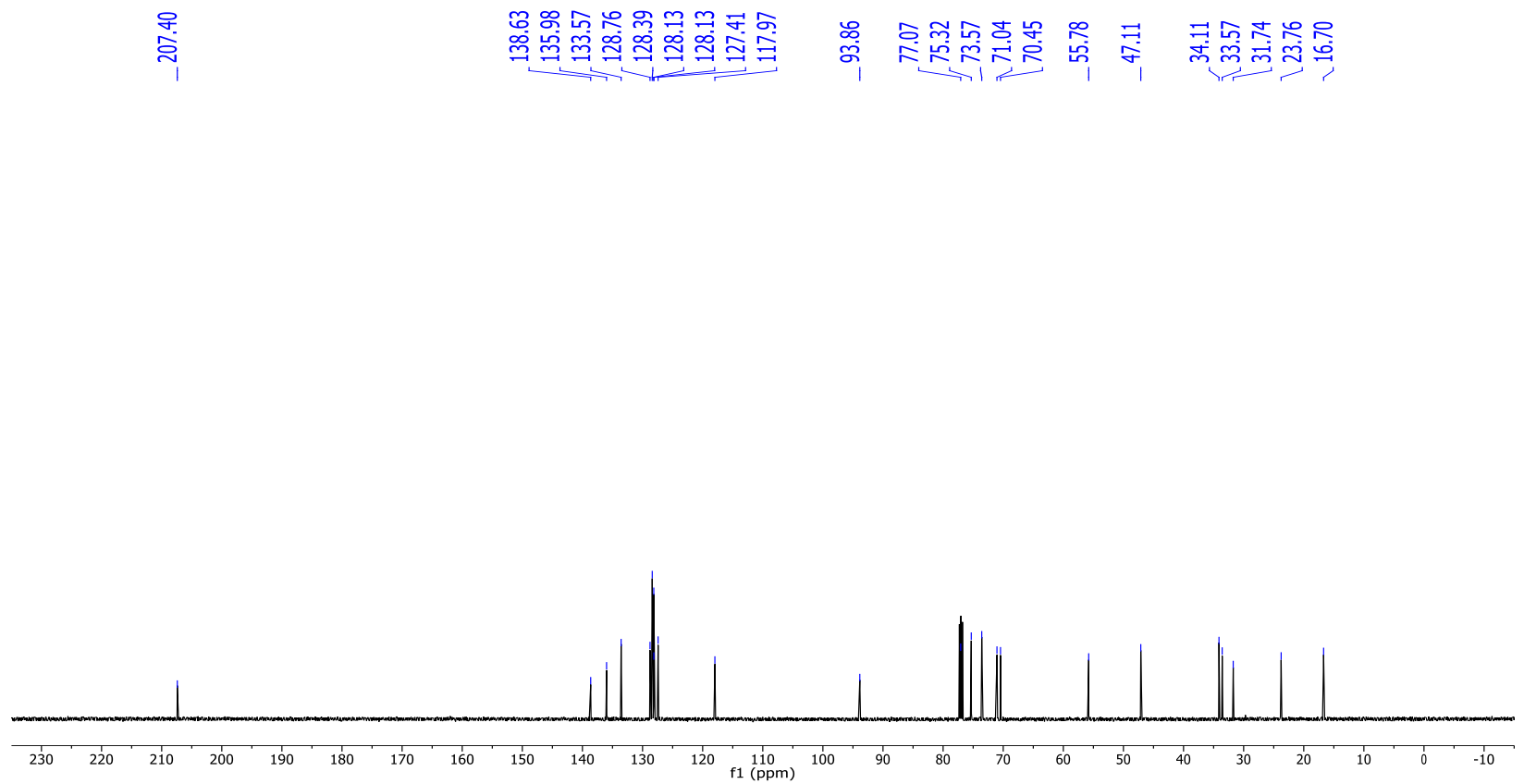


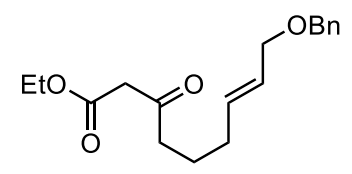

\section{Compound $25-{ }^{1} \mathrm{H}$ NMR $\left(500 \mathrm{MHz}, \mathrm{CDCl}_{3}\right)$}

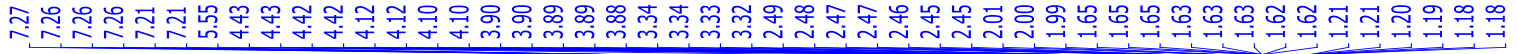
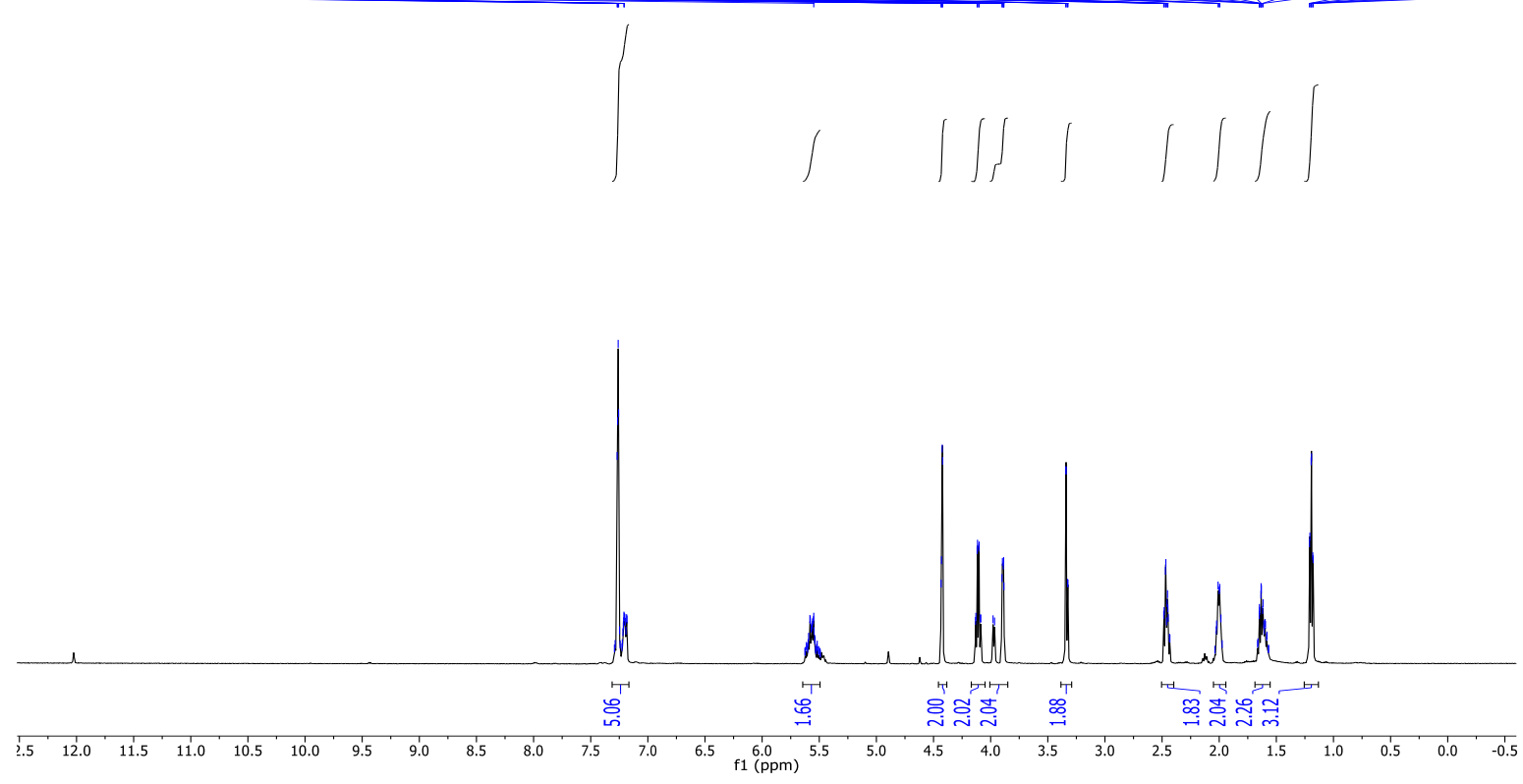

Compound $25-{ }^{13} \mathrm{C}$ NMR $\left(125 \mathrm{MHz}, \mathrm{CDCl}_{3}\right)$

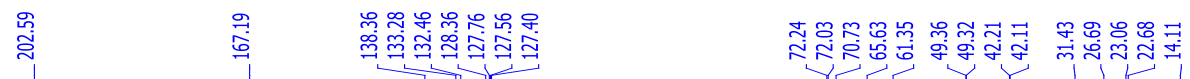

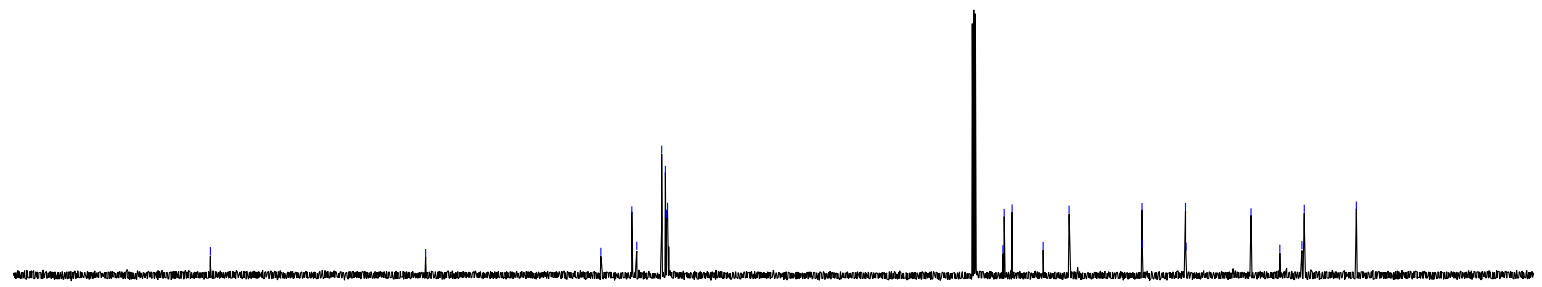

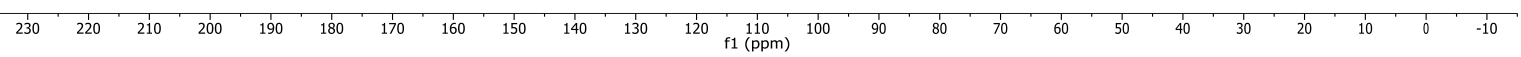


$\prod_{\mathrm{O}}^{\mathrm{EtO}}$

Compound $6-{ }^{1} \mathrm{H}$ NMR (500 MHz, $\mathrm{CDCl}_{3}$ )

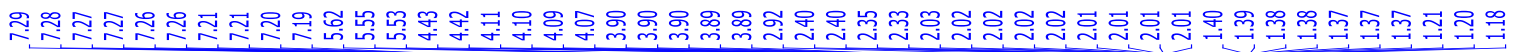
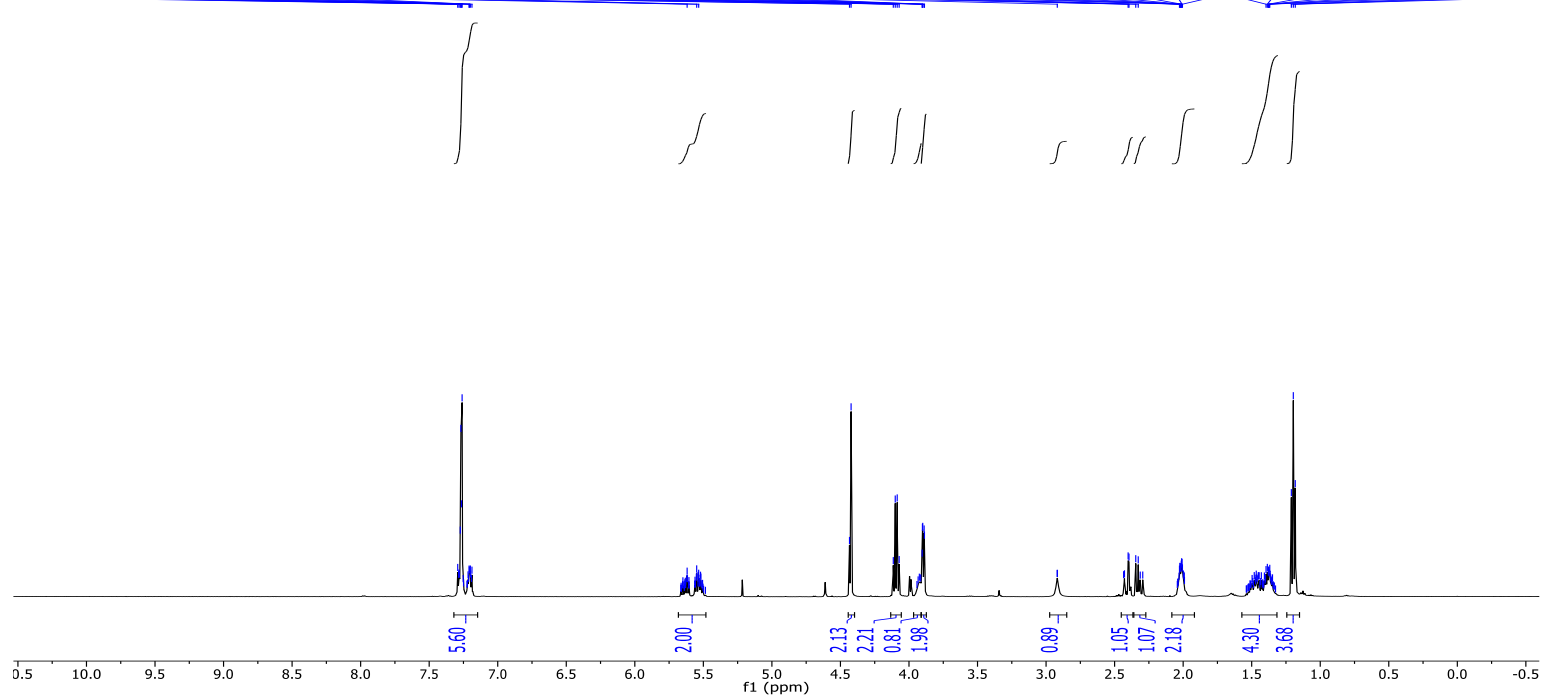

Compound 6- ${ }^{13} \mathrm{C} \mathrm{NMR}\left(125 \mathrm{MHz}, \mathrm{CDCl}_{3}\right)$

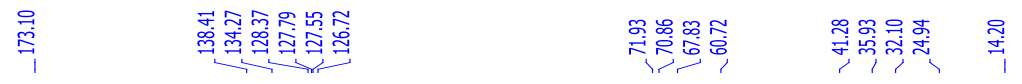

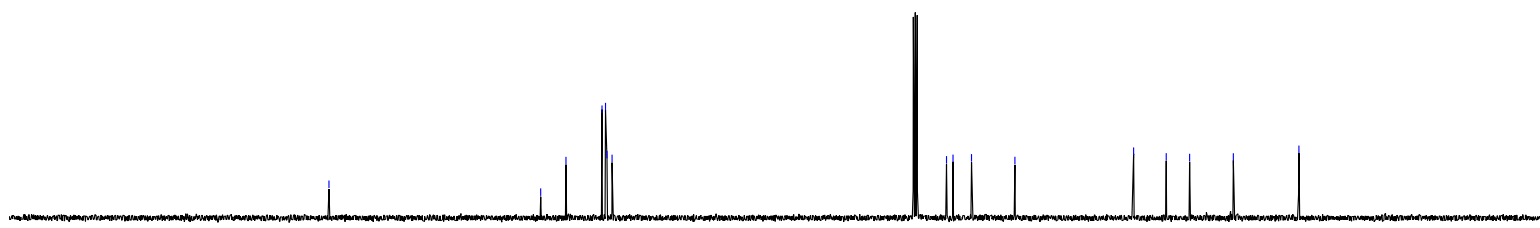

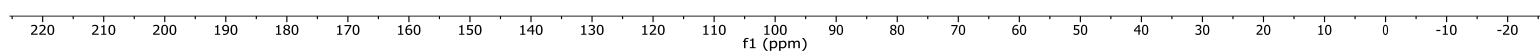

Compound 6 - chiral HPLC chromatogram

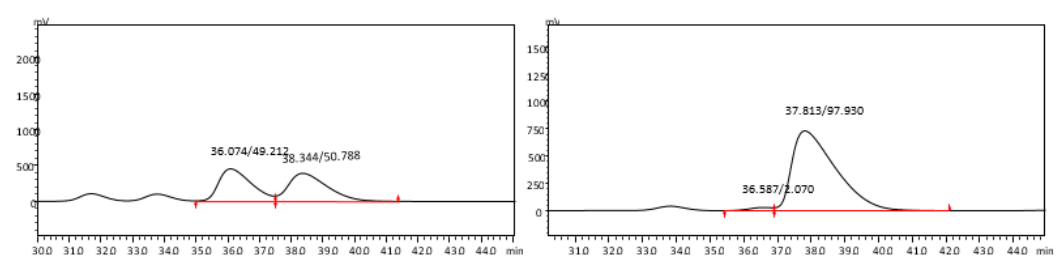




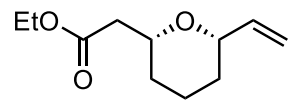

Compound $26-{ }^{1} \mathrm{H}$ NMR $\left(500 \mathrm{MHz}, \mathrm{CDCl}_{3}\right)$

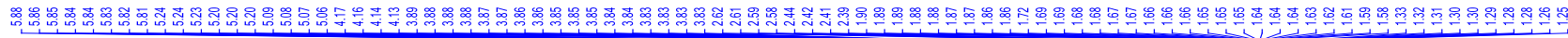
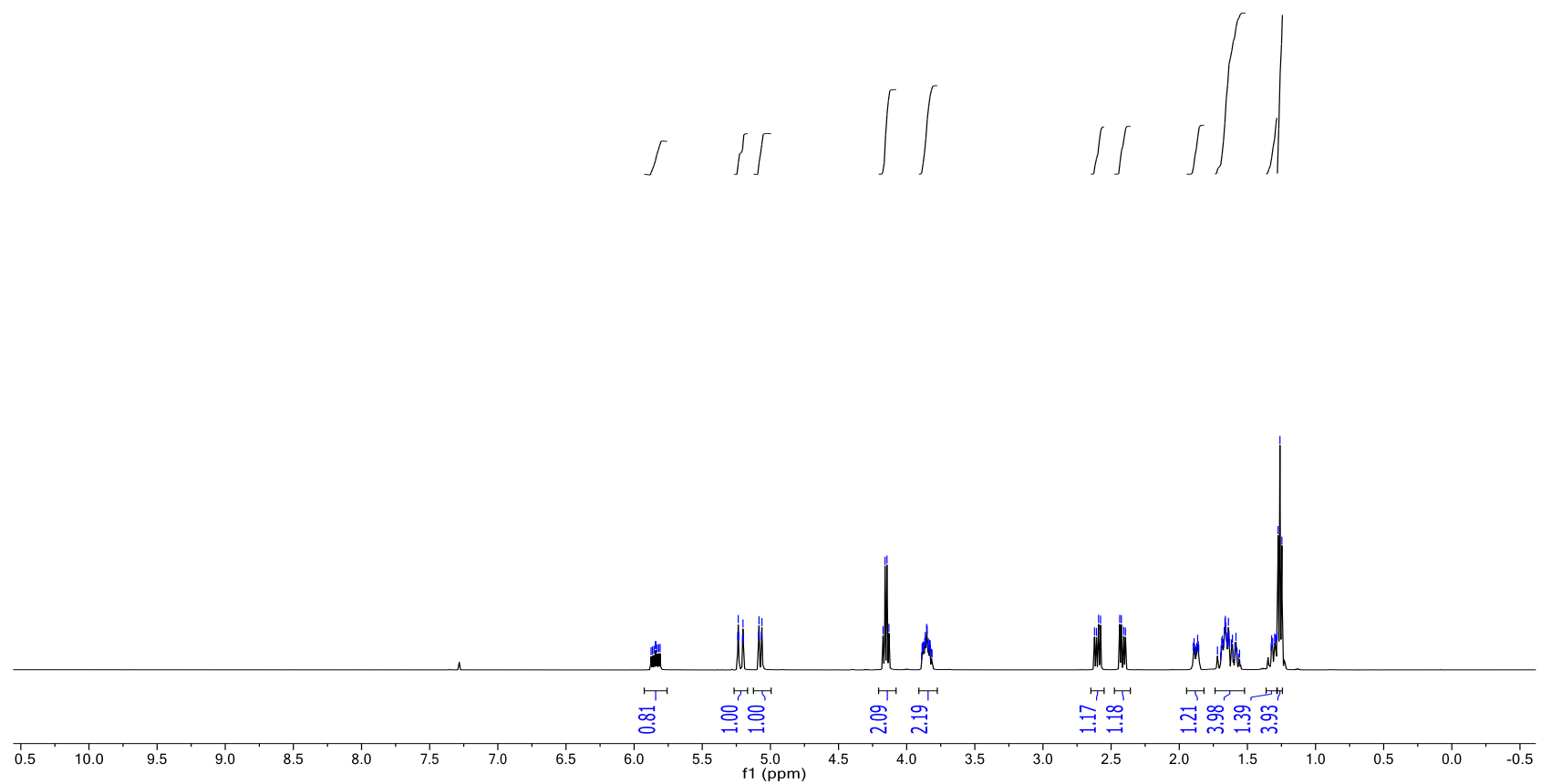

Compound $26-{ }^{13} \mathrm{C}$ NMR $\left(125 \mathrm{MHz}, \mathrm{CDCl}_{3}\right)$

突 总 兽

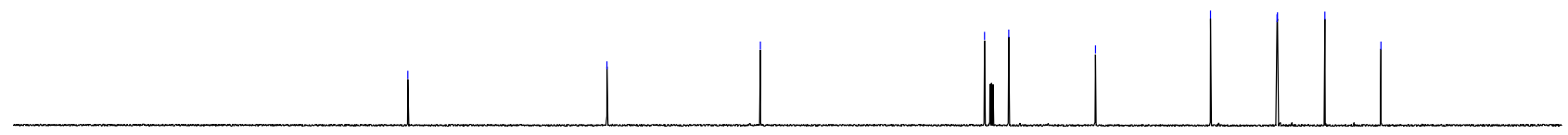

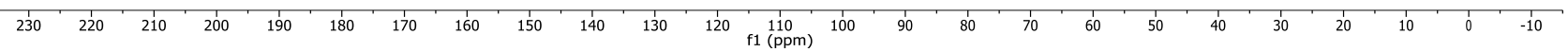




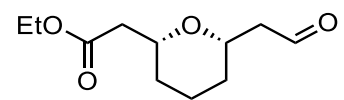

Compound $4-{ }^{1} \mathrm{H}$ NMR $\left(500 \mathrm{MHz}, \mathrm{CDCl}_{3}\right)$

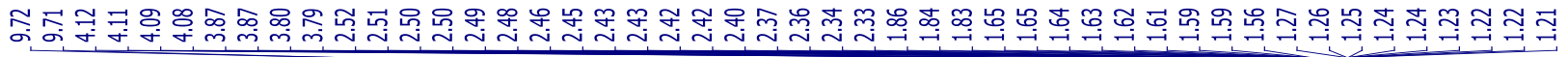
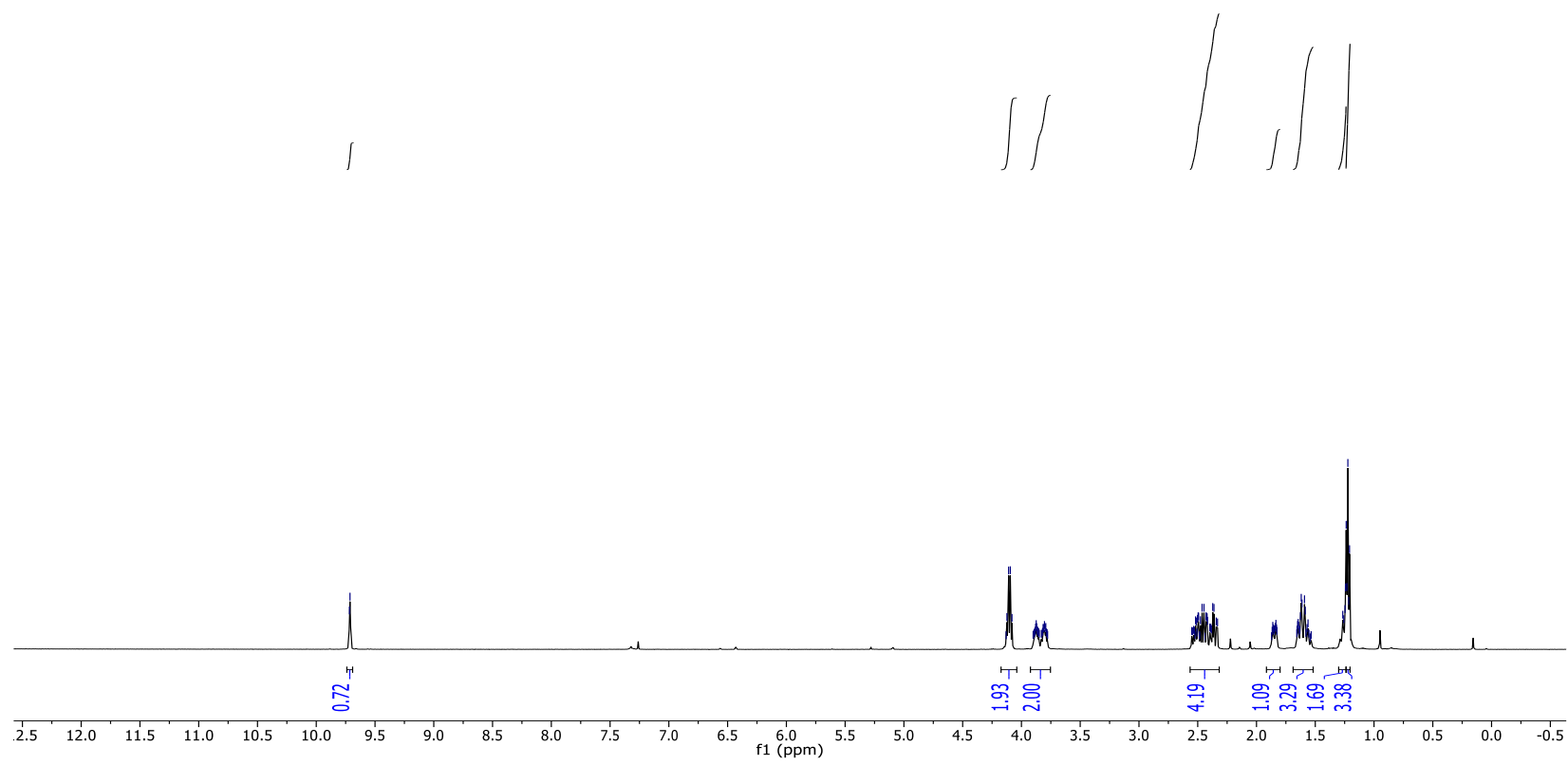

Compound $4-{ }^{13} \mathrm{C}$ NMR $\left(125 \mathrm{MHz}, \mathrm{CDCl}_{3}\right)$

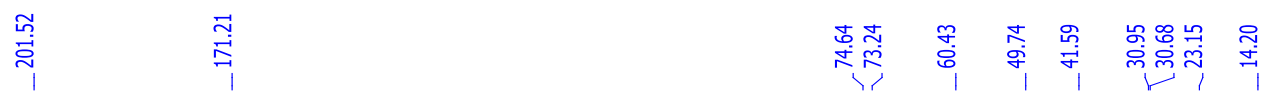

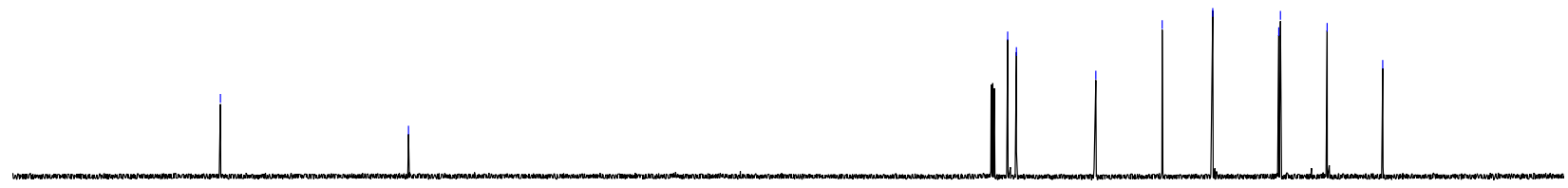

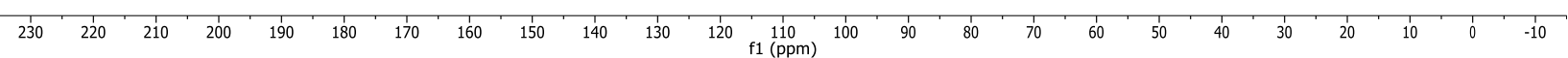




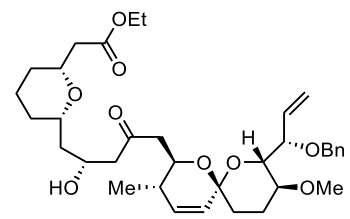

Compound $29-{ }^{1} \mathrm{H}$ NMR $\left(500 \mathrm{MHz}, \mathrm{CDCl}_{3}\right)$

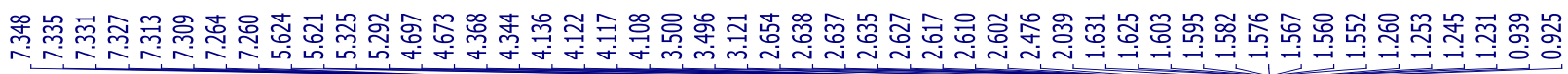

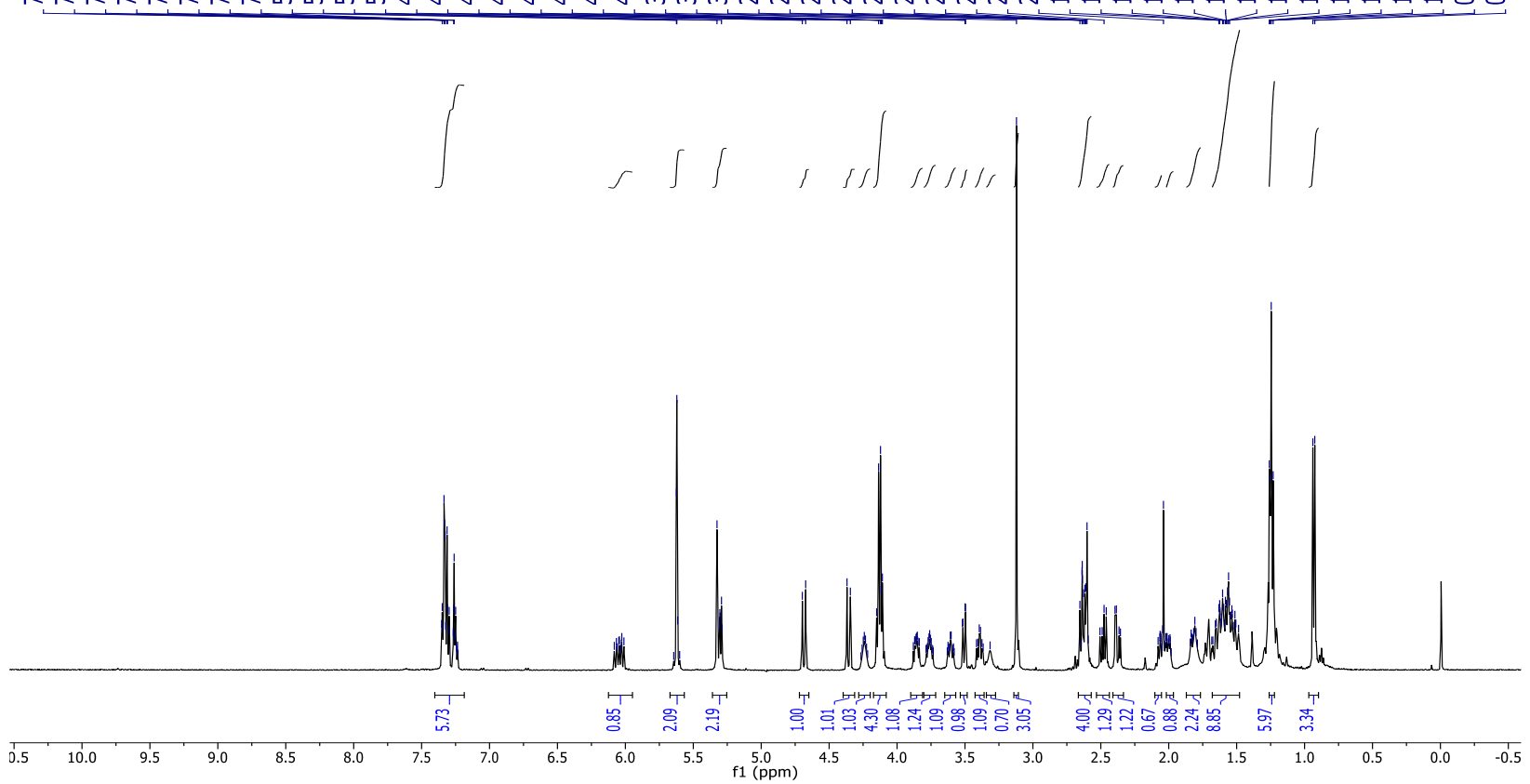

Compound $29-{ }^{13} \mathrm{C}$ NMR (125 MHz, $\left.\mathrm{CDCl}_{3}\right)$

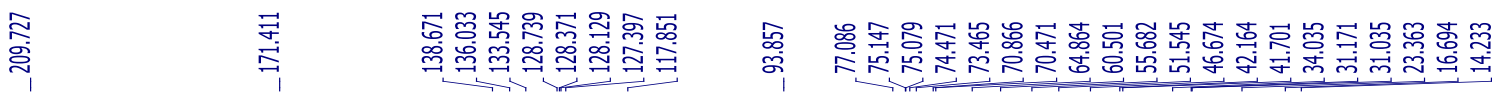

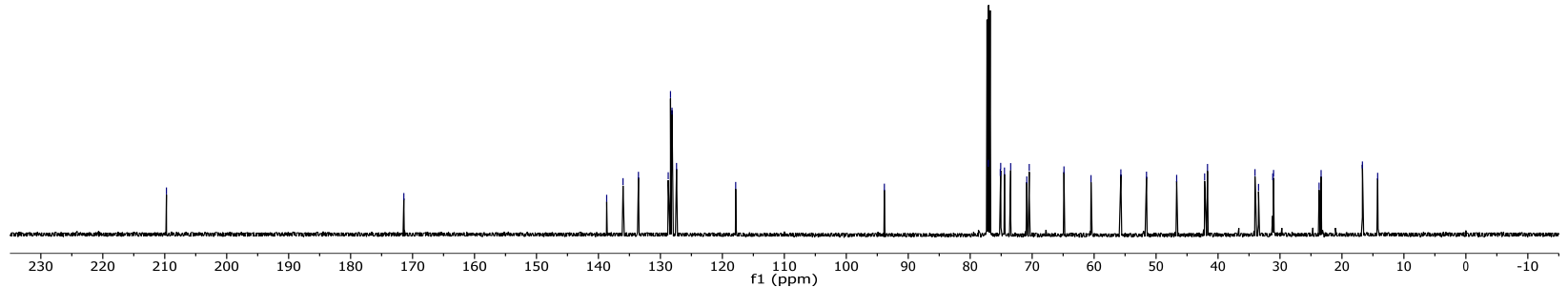




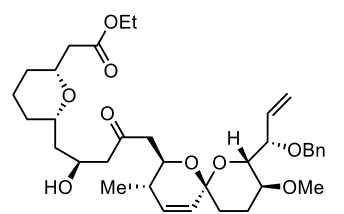

Compound $30-{ }^{1} \mathrm{H}$ NMR $\left(500 \mathrm{MHz}, \mathrm{CDCl}_{3}\right)$

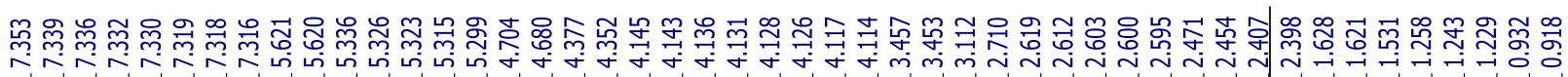

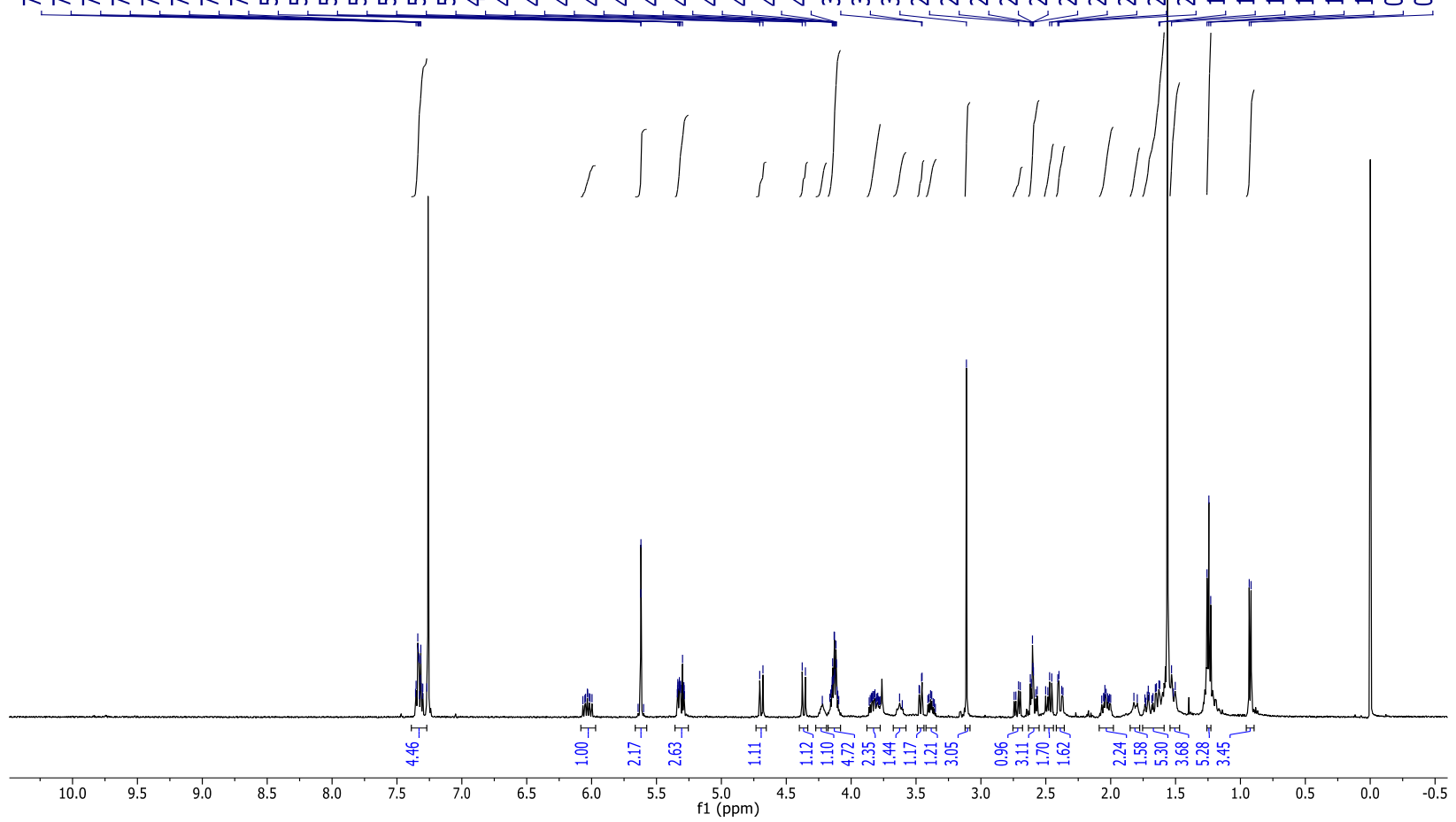

Compound $30-{ }^{13} \mathrm{C}$ NMR (125 MHz, $\mathrm{CDCl}_{3}$ )

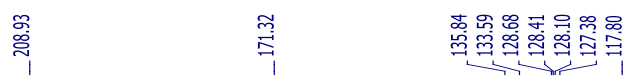

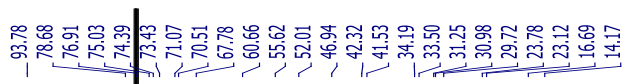

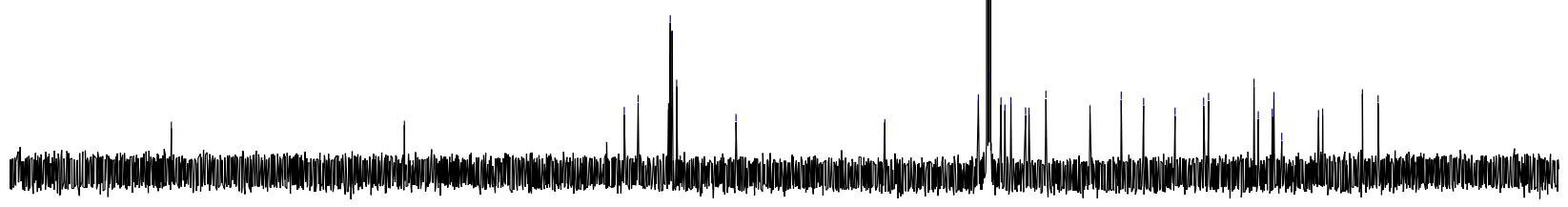

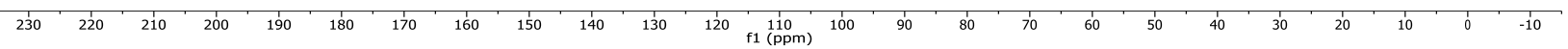




\section{Mosher's ester analysis of aldol adduct from Mukiyama aldol:}

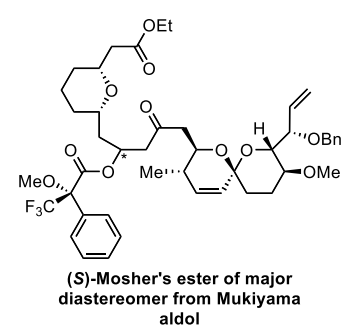

${ }^{1} \mathrm{H}$ NMR (500 MHz, $\left.\mathrm{CDCl}_{3}\right)$

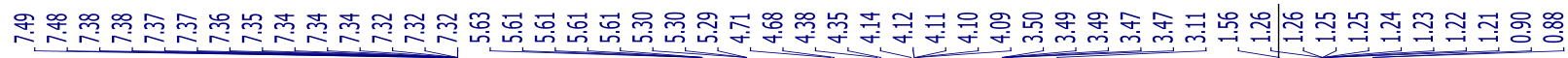
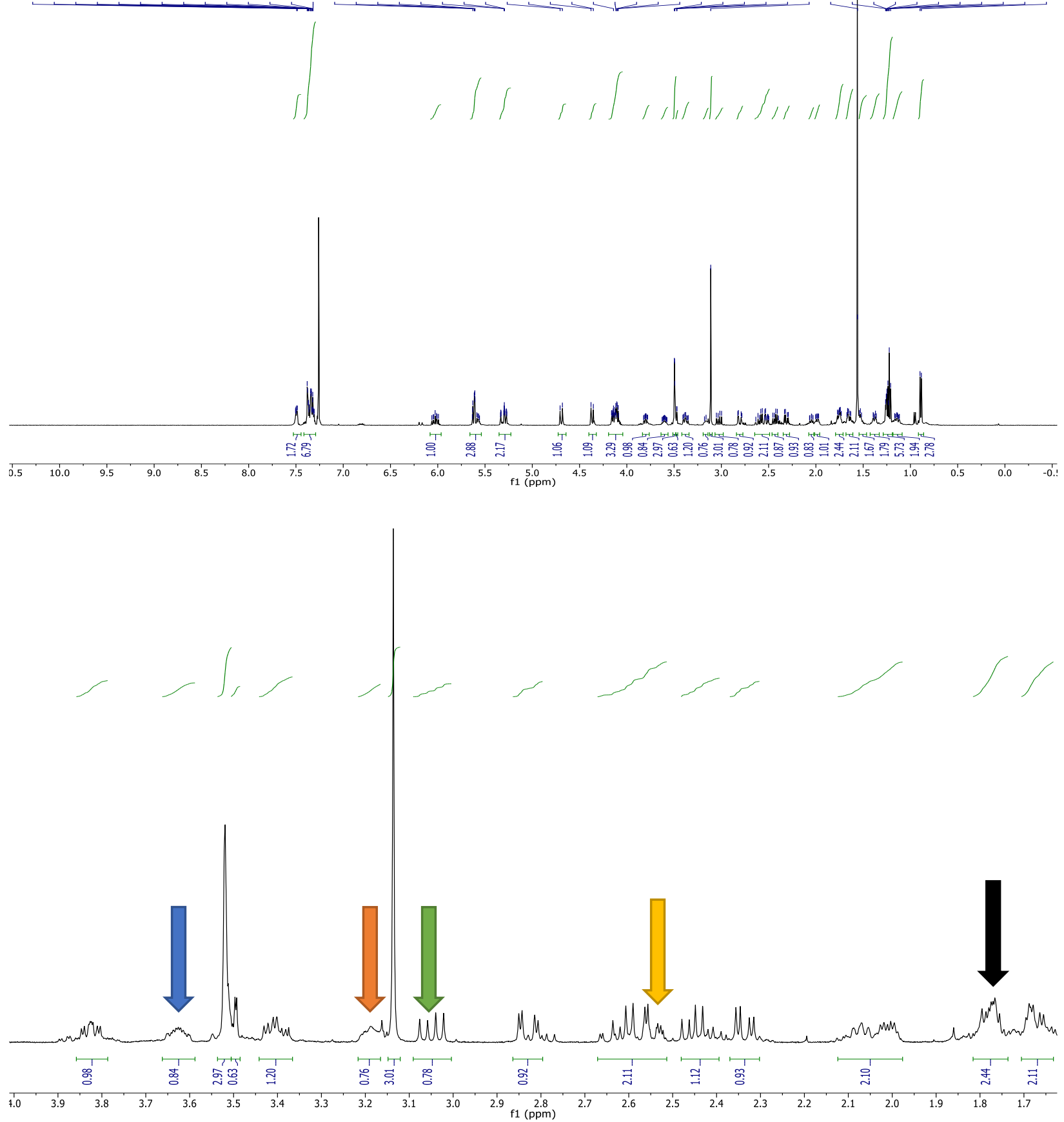
${ }^{13} \mathrm{C}$ NMR $\left(150 \mathrm{MHz}, \mathrm{CDCl}_{3}\right)$

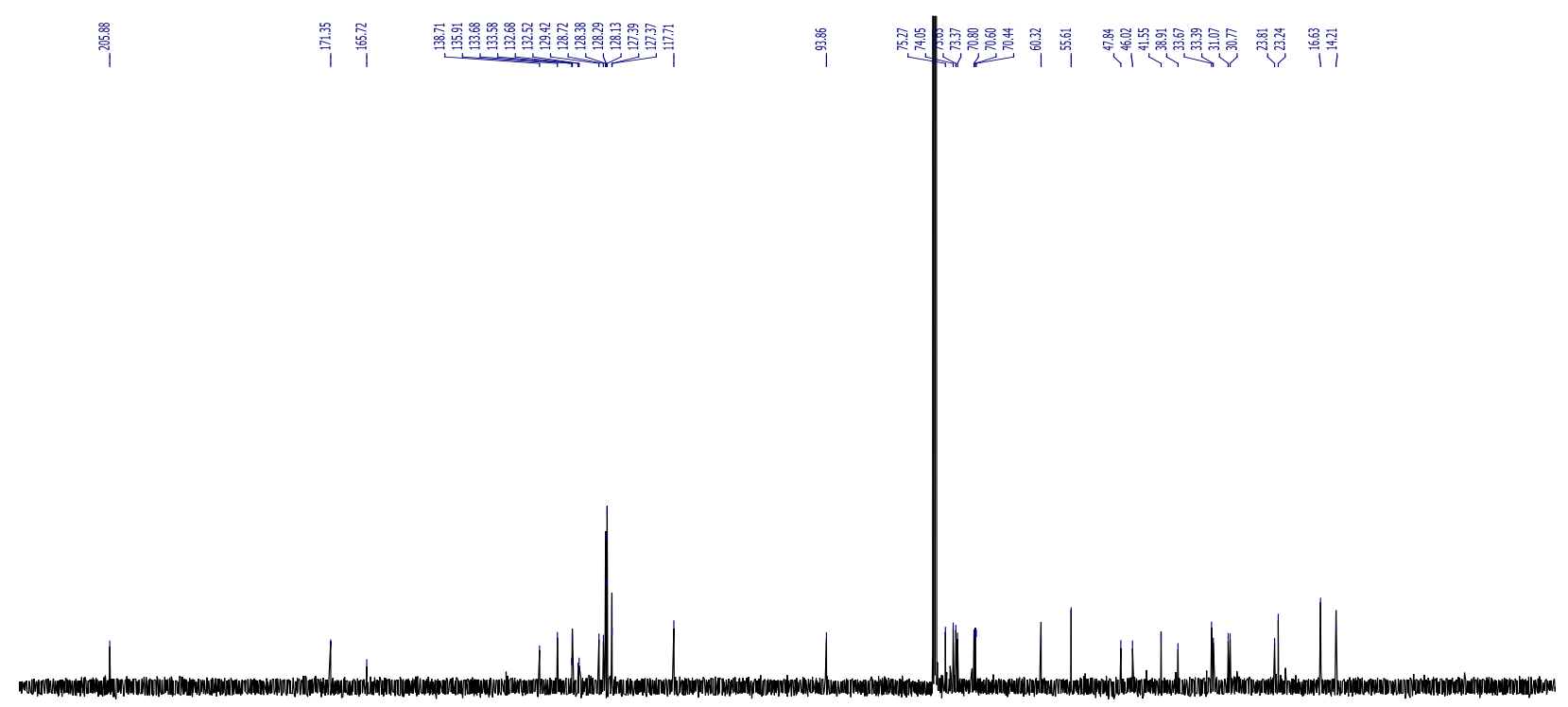

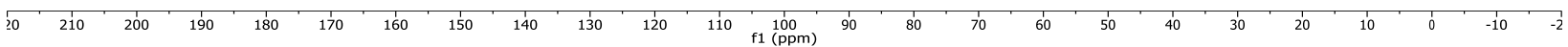

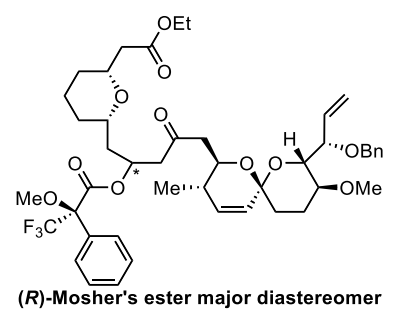

of Mukiyama aldol reaction

${ }^{1} \mathrm{H} \mathrm{NMR}\left(500 \mathrm{MHz}, \mathrm{CDCl}_{3}\right.$ )

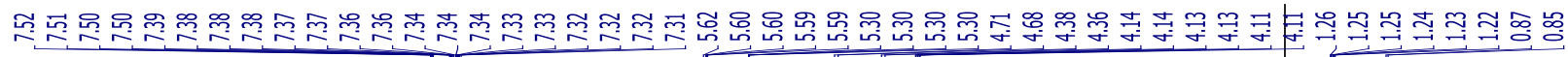

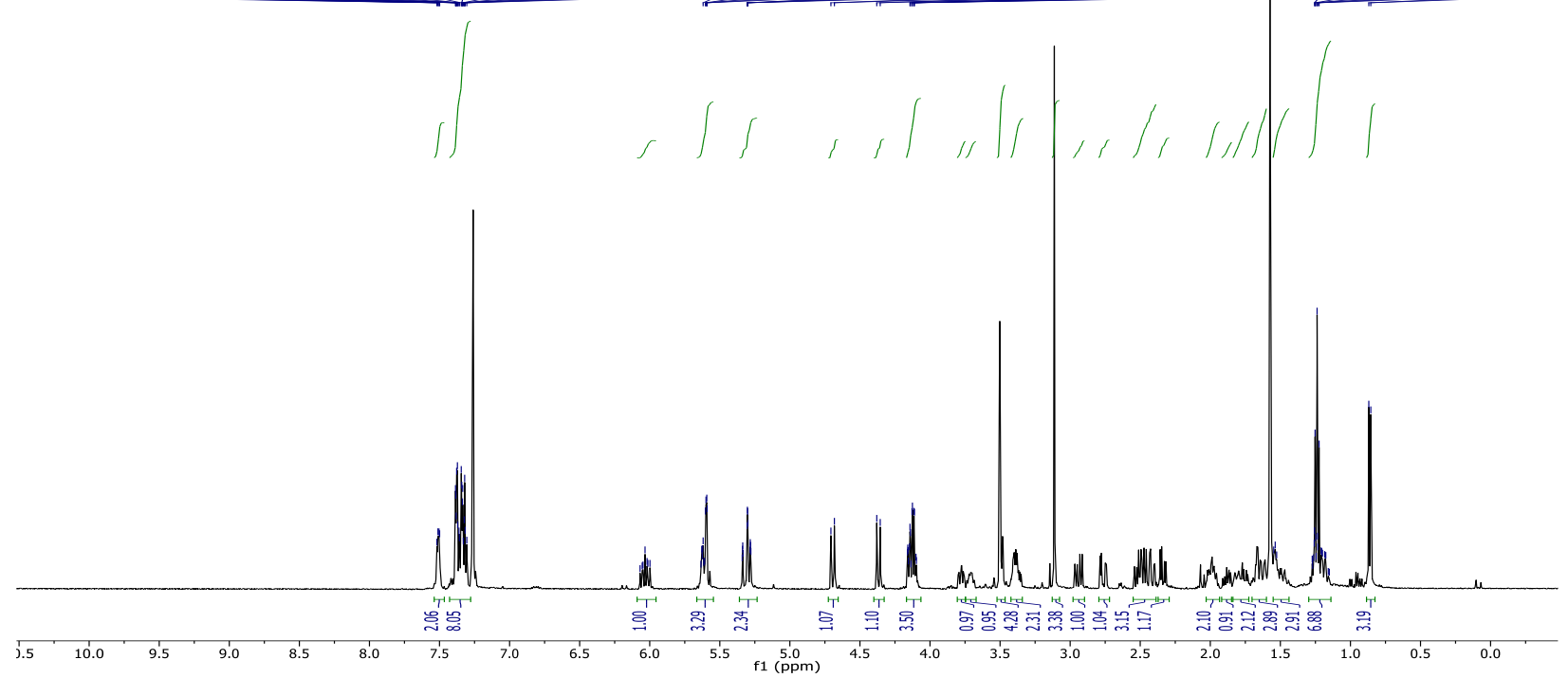




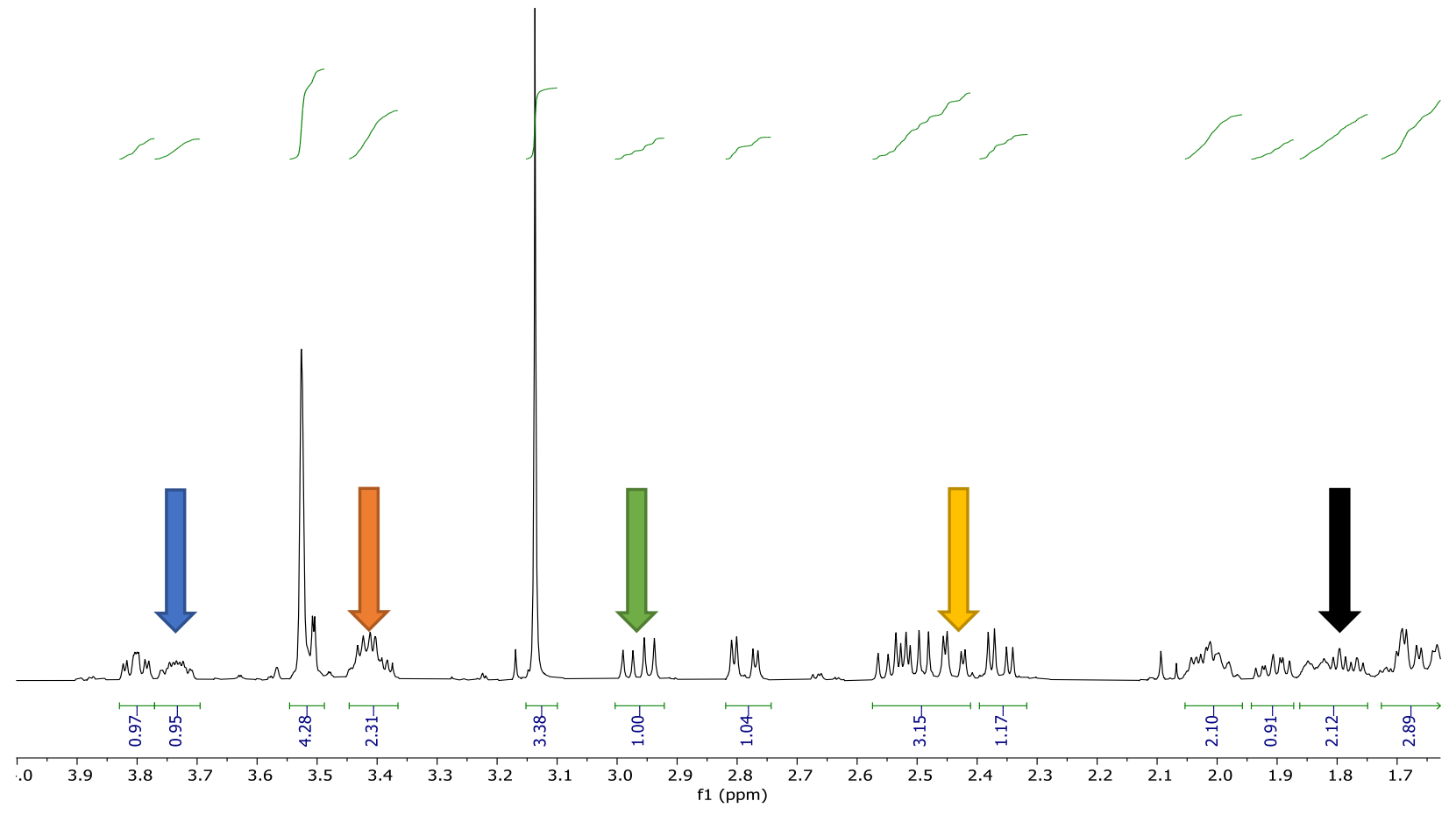

${ }^{13} \mathrm{C}$ NMR (150 MHz, $\left.\mathrm{CDCl}_{3}\right)$

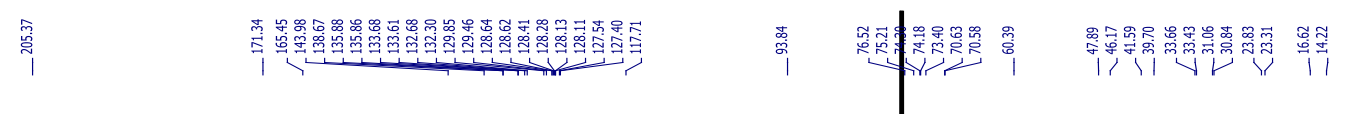

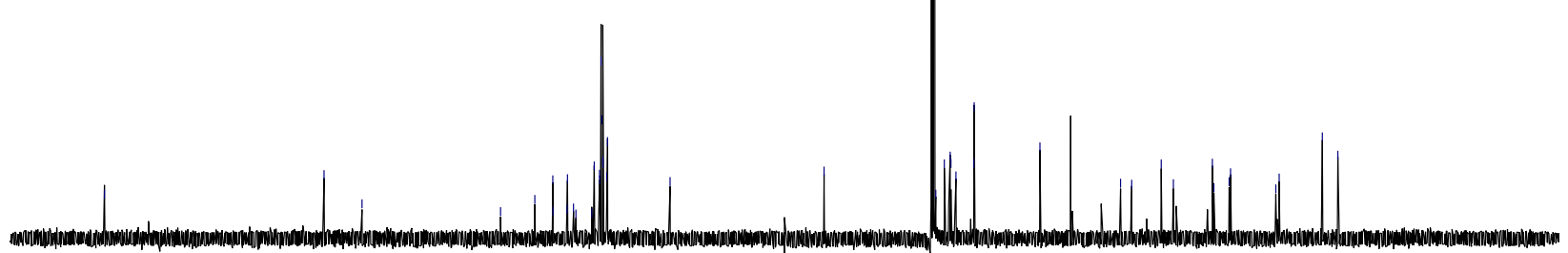

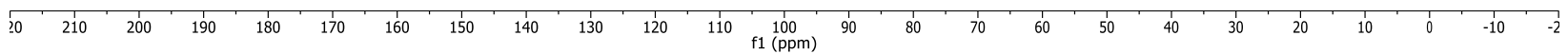




\section{Figure S1. Mosher's ester analysis}
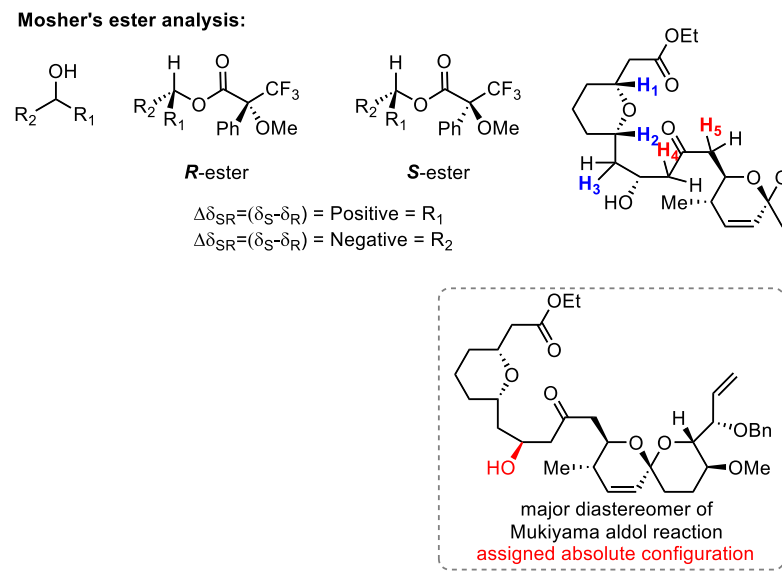
$\Delta \delta_{\mathrm{SR}}=\left(\delta_{\mathrm{S}}-\delta_{\mathrm{R}}\right)=$ Negative $=\mathrm{R}_{2}$

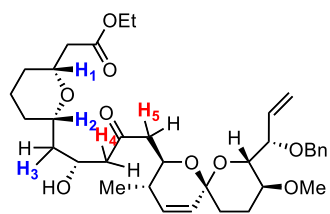

\begin{tabular}{ccc} 
(S)-ester & \multicolumn{2}{c}{$(R)$-ester $\Delta \delta_{\mathrm{SR}}=\left(\delta_{\left.\mathrm{S}^{-}-\delta_{\mathrm{R}}\right)}\right.$} \\
$\mathrm{H}_{1}=3.63$ & 3.73 & -0.10 \\
$\mathrm{H}_{2}=3.19$ & 3.42 & -0.23 \\
$\mathrm{H}_{3}=1.78$ & 1.90 & -0.12 \\
$\mathrm{H}_{4}=3.05$ & 2.95 & +0.10 \\
$\mathrm{H}_{5}=2.53$ & 2.43 & +0.10 \\
\multicolumn{3}{c}{} \\
$\mathrm{R}_{1}=$ Spiroketal \\
$\mathrm{R}_{2}=$ Pyran
\end{tabular}
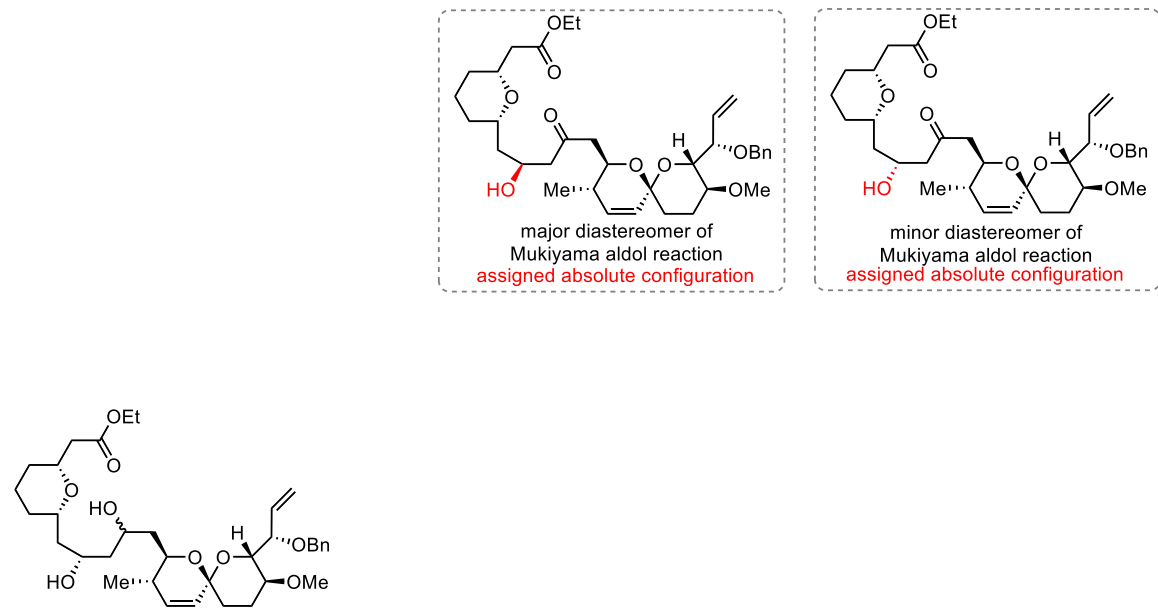

Compound 34 (mixture of diastereomers) - ${ }^{1} \mathrm{H}$ NMR (500 MHz, $\mathrm{CDCl}_{3}$ )

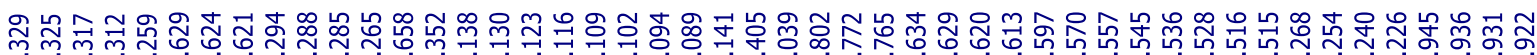

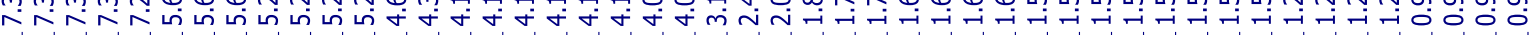
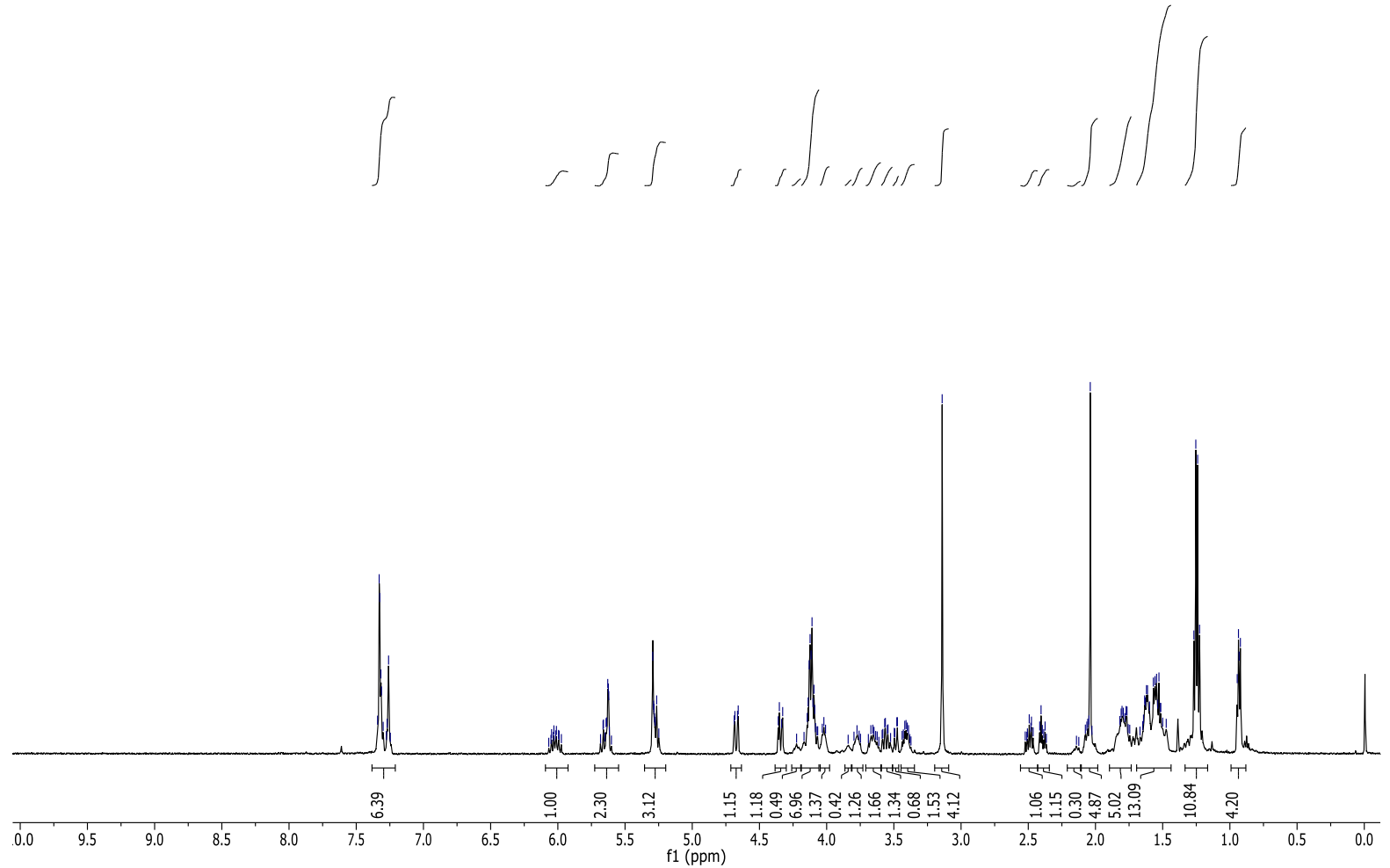
Compound 34 (mixture of diastereomers) $-{ }^{13} \mathrm{C} \mathrm{NMR}\left(125 \mathrm{MHz}, \mathrm{CDCl}_{3}\right)$
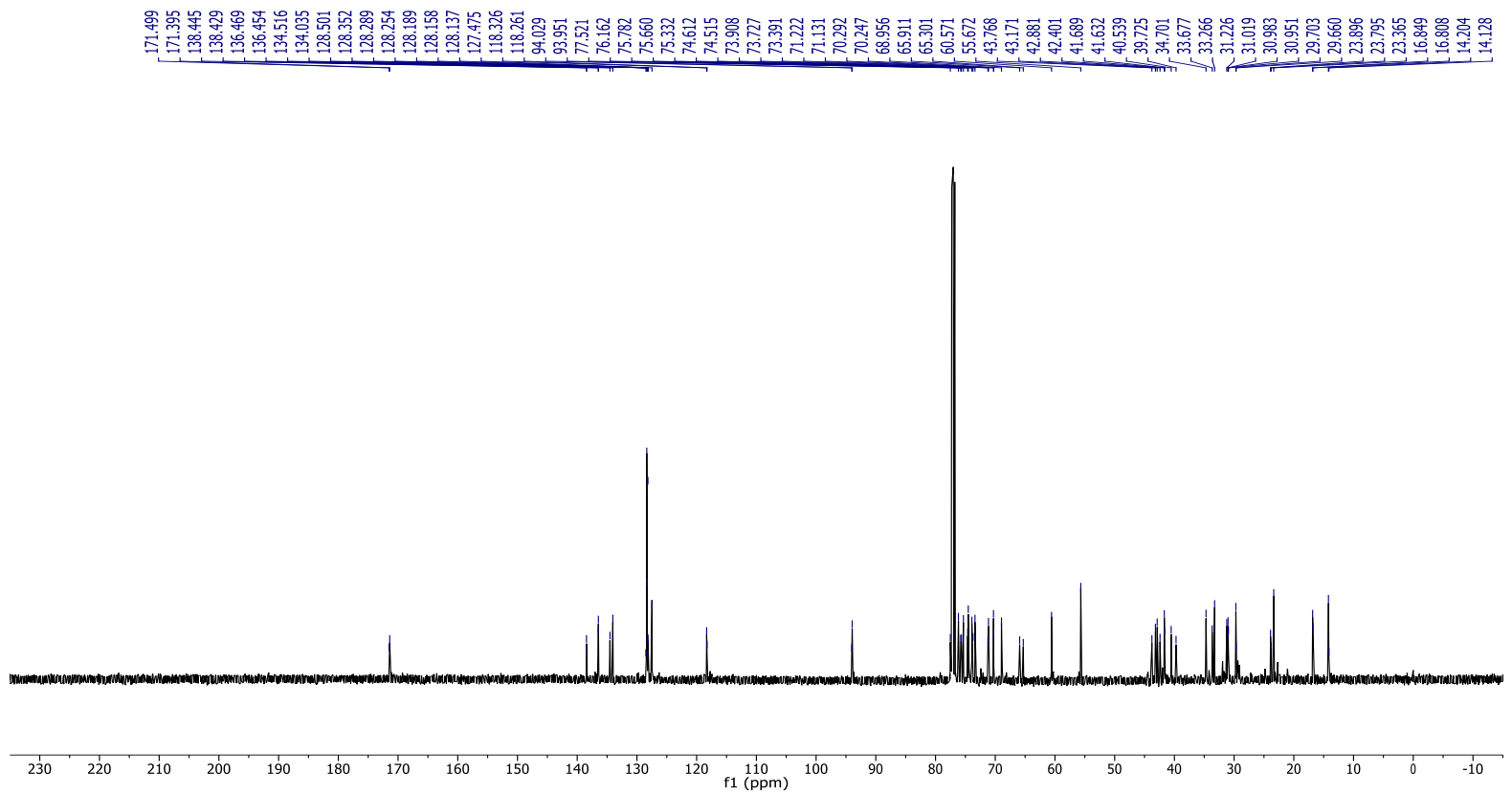

Determination of relative stereochemistry of C20-C23 diol (Rychnovsky's protocol):

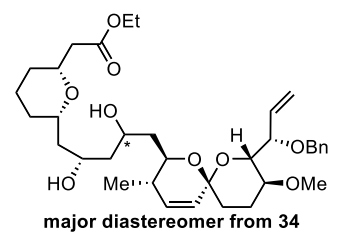

Compound 34 (major diastereomer) - ${ }^{1} \mathrm{H}$ NMR $\left(500 \mathrm{MHz}, \mathrm{CDCl}_{3}\right)$

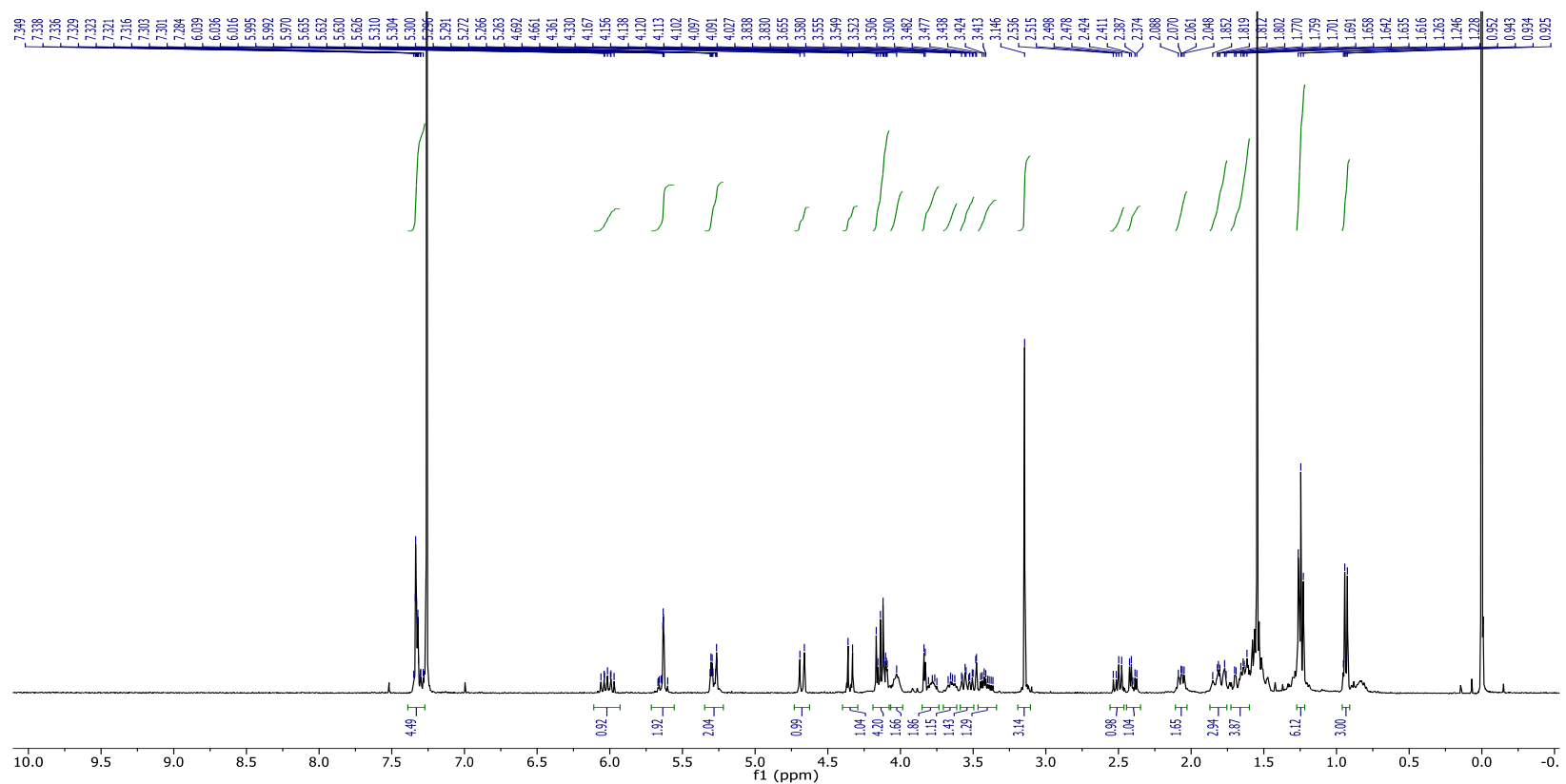




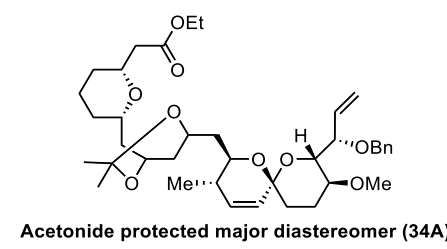

Compound 34A $-{ }^{1} \mathrm{H}$ NMR (600 MHz, $\left.\mathrm{CDCl}_{3}\right)$
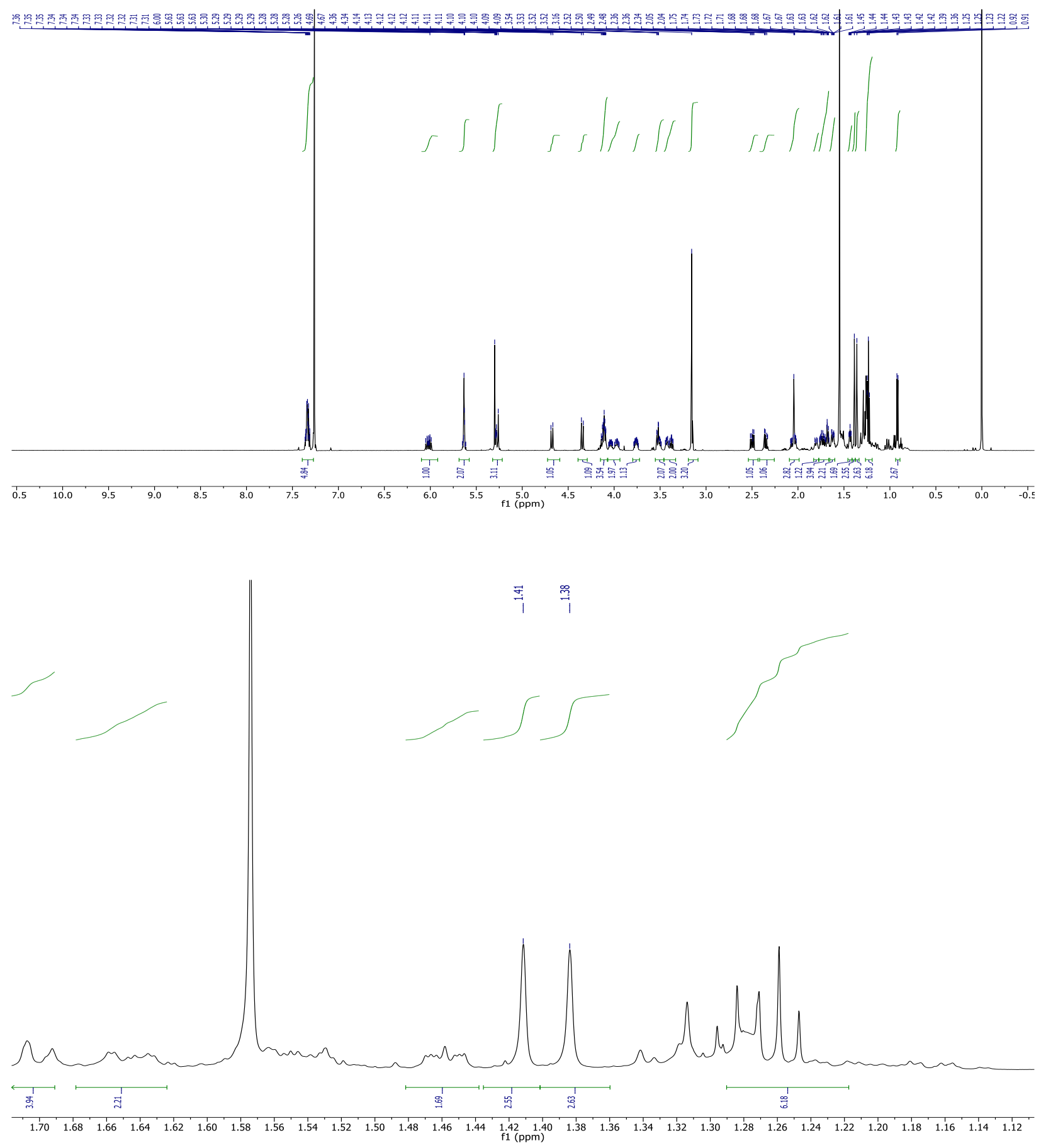
Compound 34A - HSQC (600 MHz, $\mathrm{CDCl}_{3}$ )
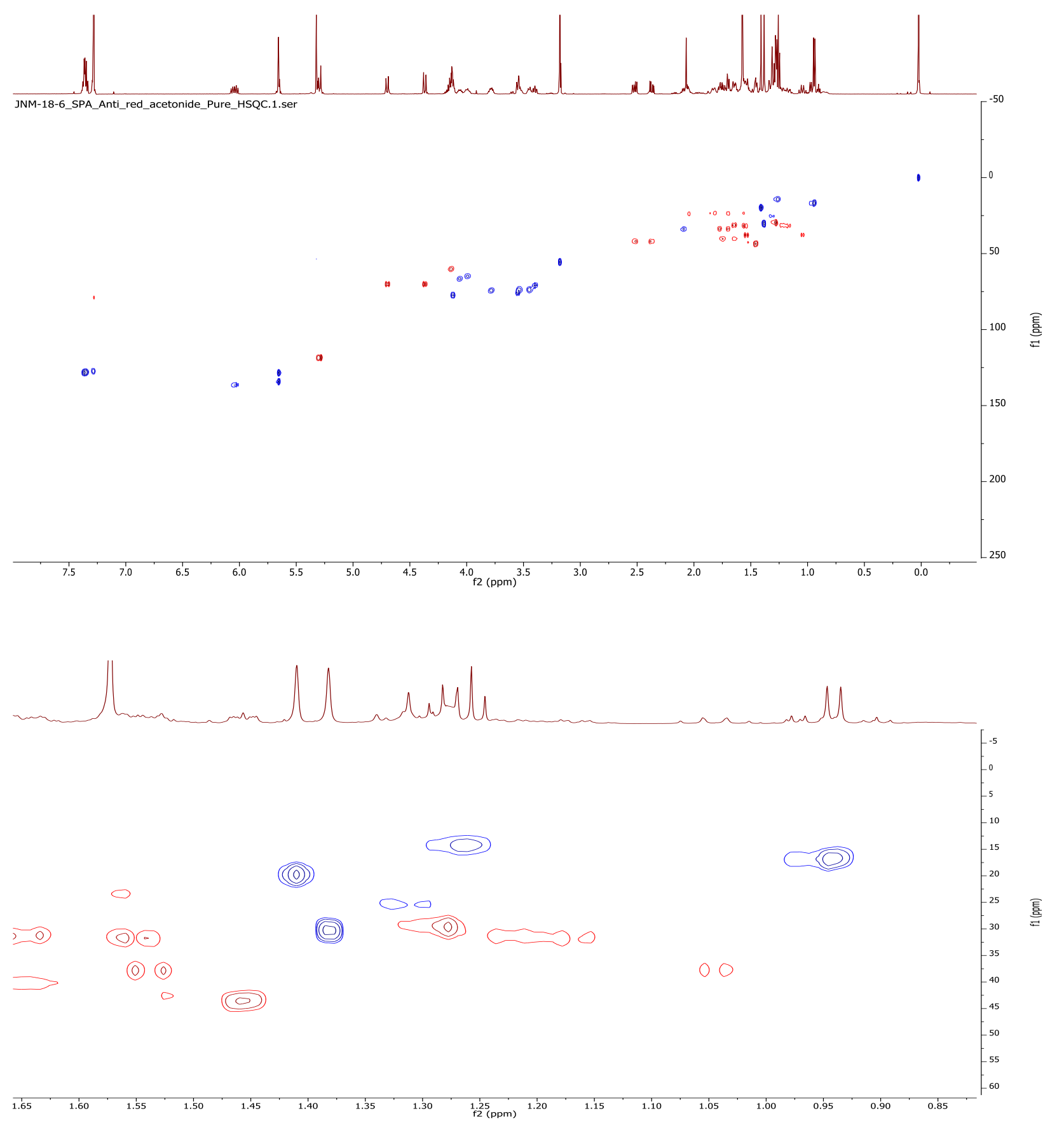
Compound 34A - COSY (100 MHz, $\left.\mathrm{CDCl}_{3}\right)$

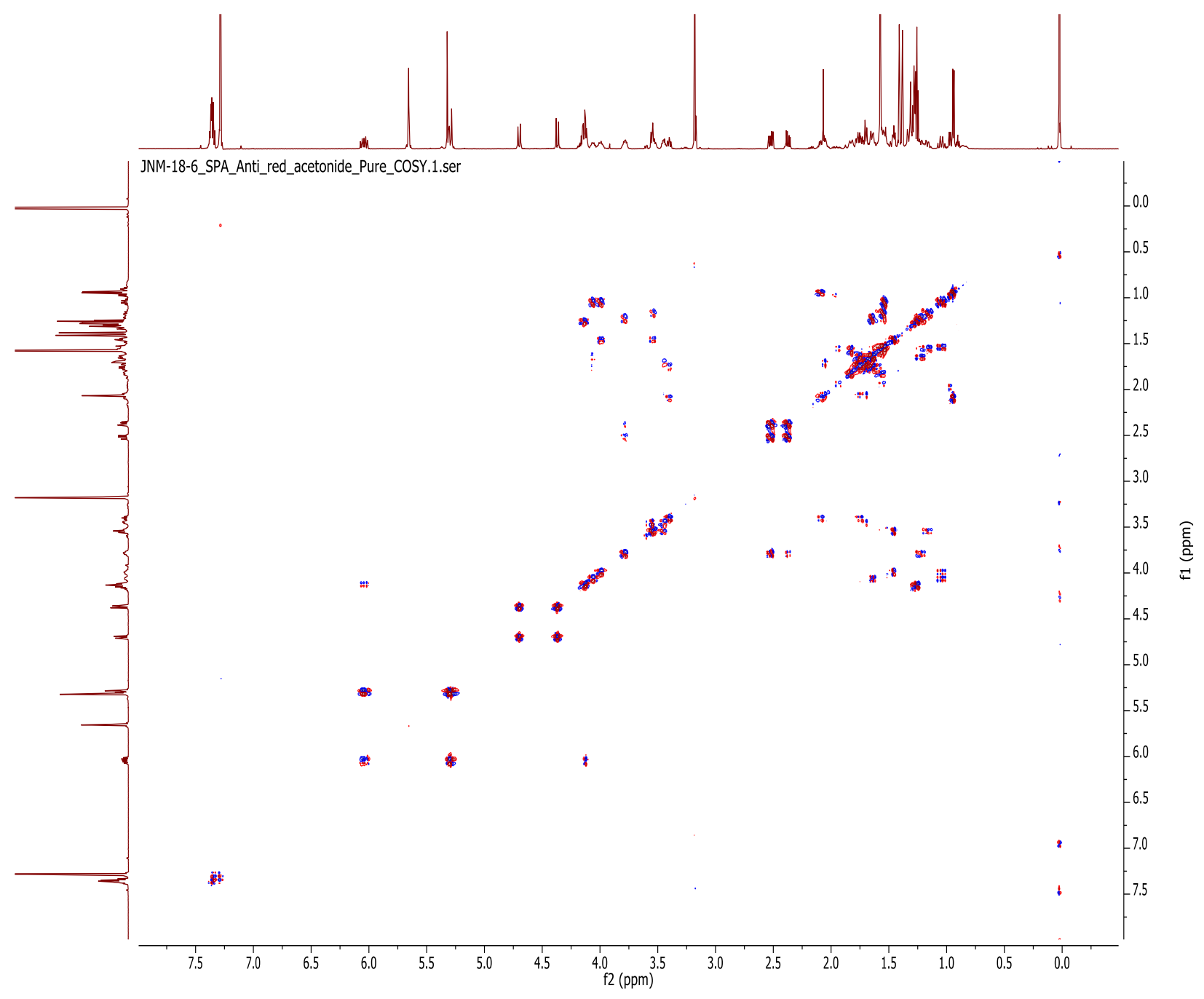

Figure S2. Determination of relative stereochemistry of C20-C23 diol
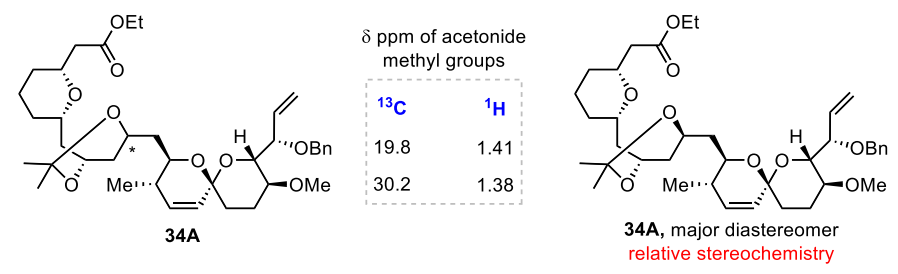


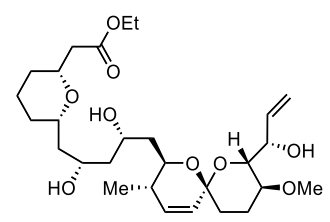

Compound $3-{ }^{1} \mathrm{H}$ NMR (600 MHz, $\mathrm{CDCl}_{3}$ )

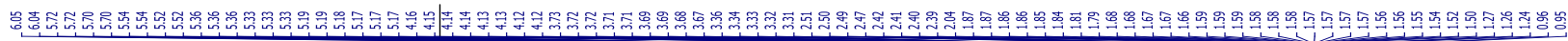

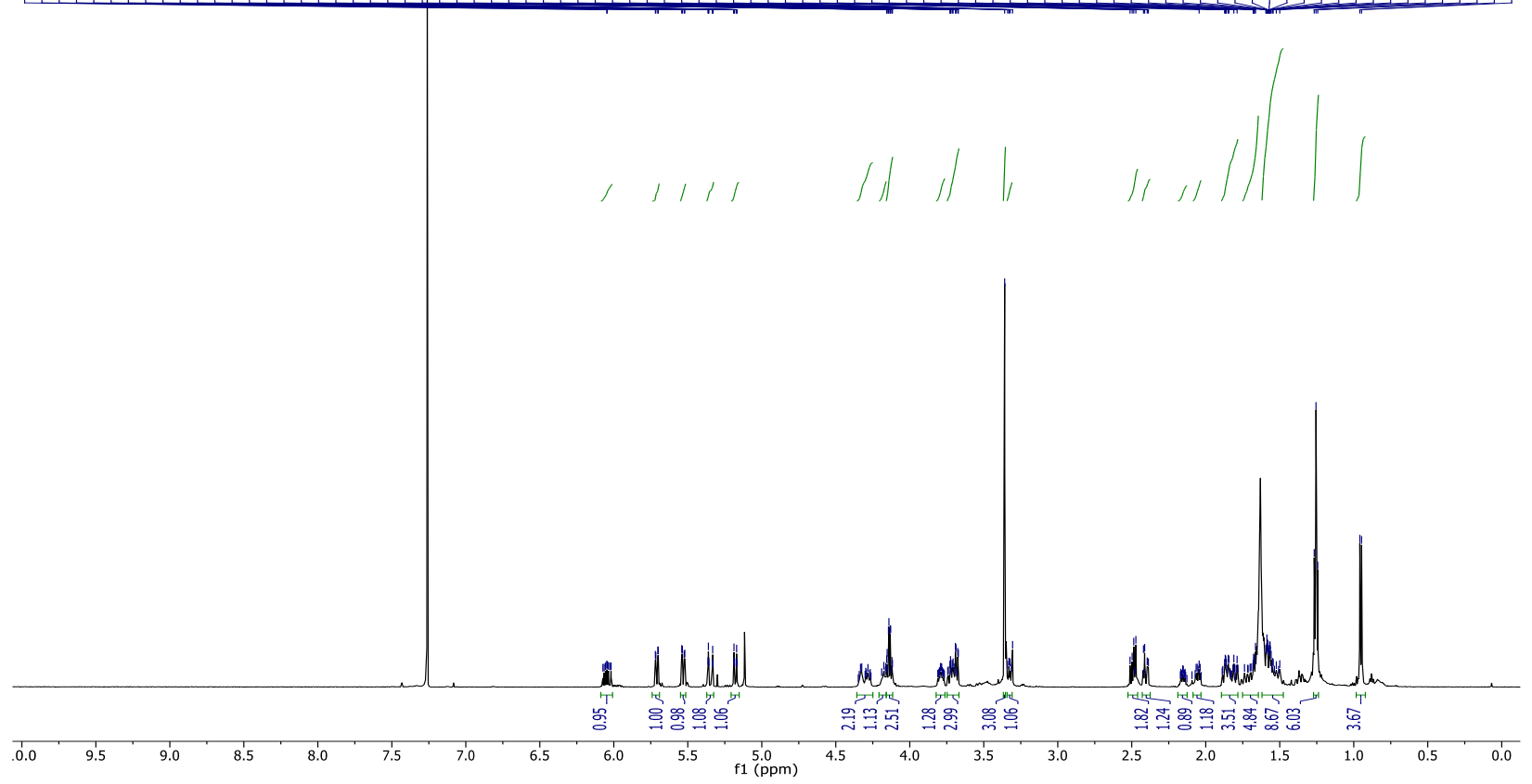

Compound $3-{ }^{13} \mathrm{C}$ NMR $\left(150 \mathrm{MHz}, \mathrm{CDCl}_{3}\right)$

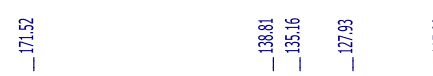

$\stackrel{8}{\stackrel{8}{g}}$

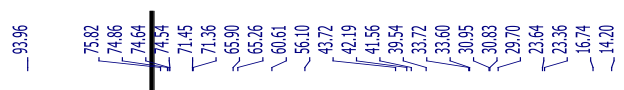

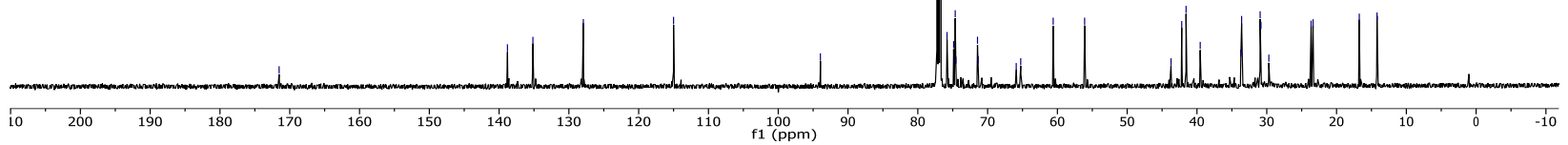




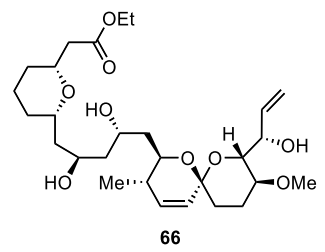

Compound $35-{ }^{1} \mathrm{H}$ NMR (600 MHz, $\left.\mathrm{CDCl}_{3}\right)$

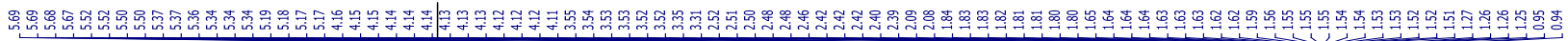

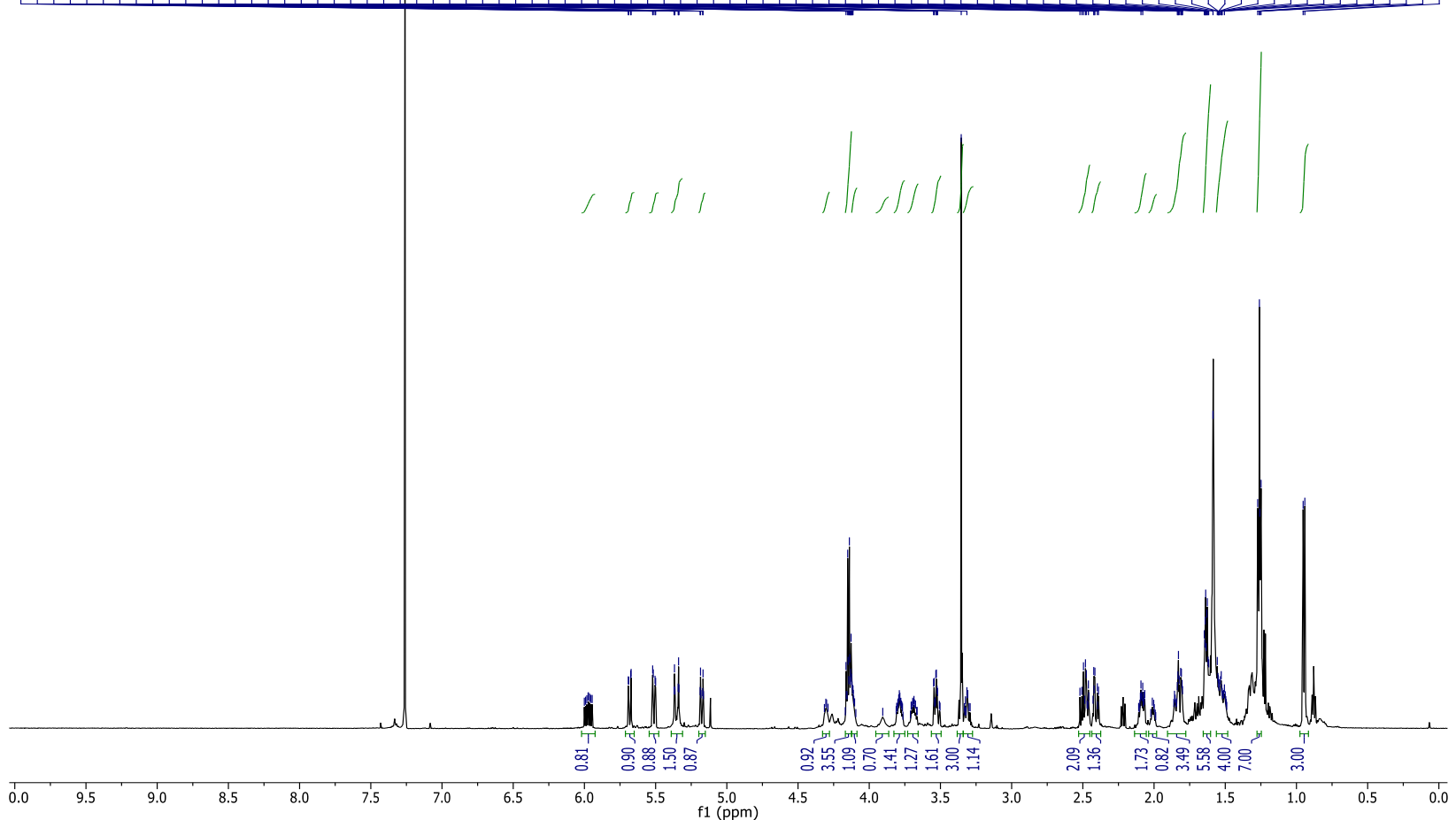

Compound $35-{ }^{13} \mathrm{C}$ NMR $\left(150 \mathrm{MHz}, \mathrm{CDCl}_{3}\right)$
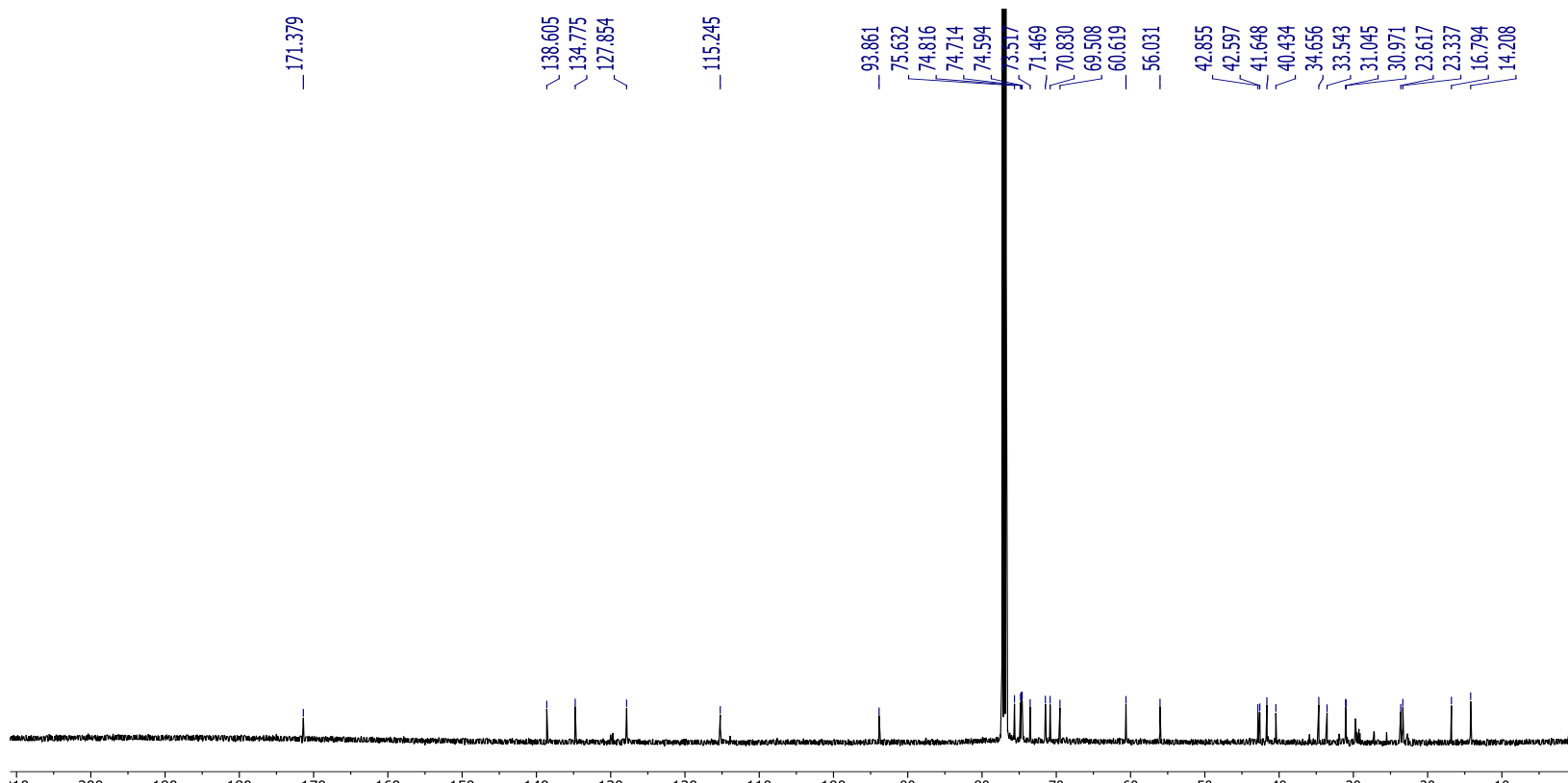

\begin{tabular}{lllllllllll}
\hline 10 & 200 & 190 & 180 & 170 & 160 & 150 & 140 & 130 & 120 & $\underset{\mathrm{f} 1(\mathrm{ppm})}{1})^{1}{ }^{\prime}$
\end{tabular} 


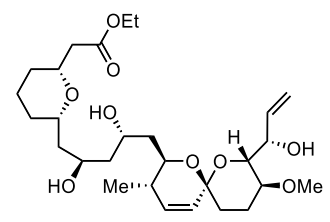

Compound $37-{ }^{1} \mathrm{H}$ NMR $\left(500 \mathrm{MHz}, \mathrm{CDCl}_{3}\right)$

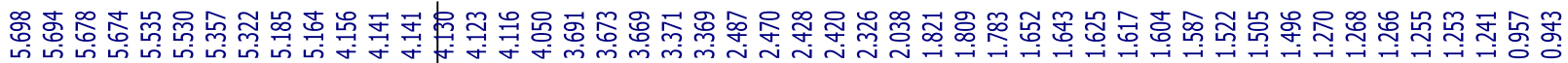

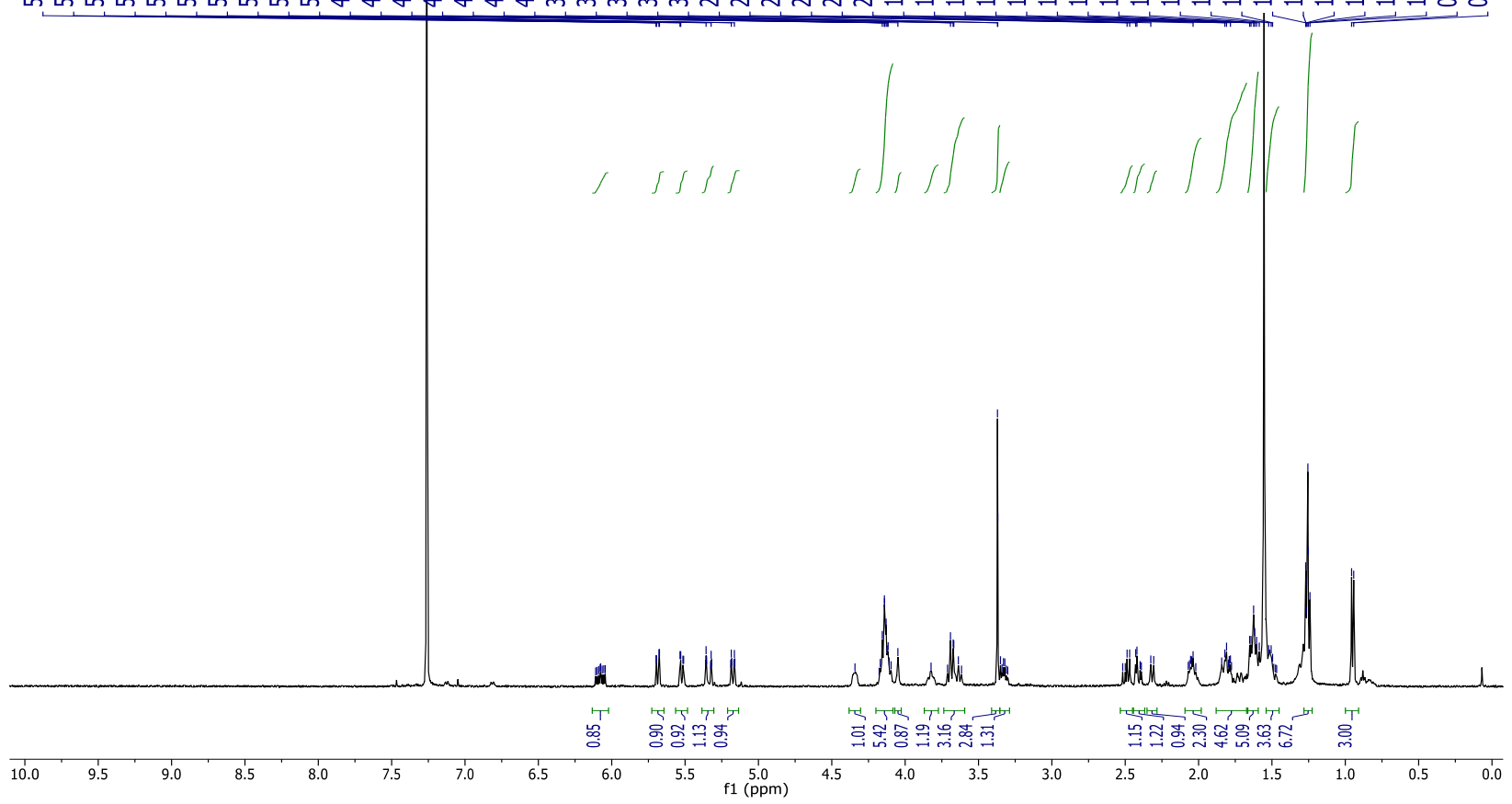

Compound $37-{ }^{13} \mathrm{C}$ NMR (125 MHz, $\mathrm{CDCl}_{3}$ )

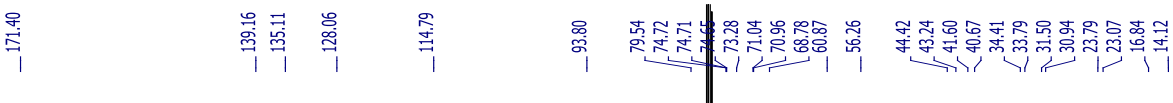

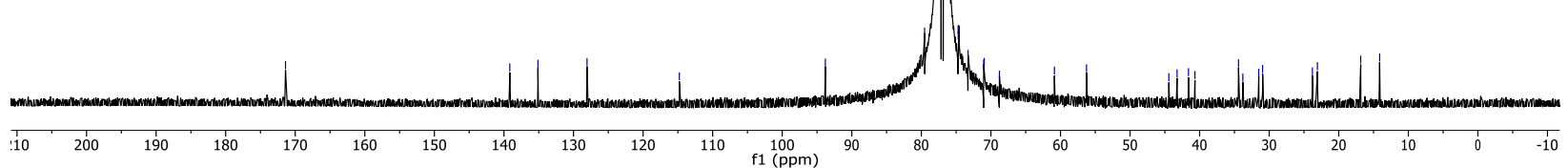




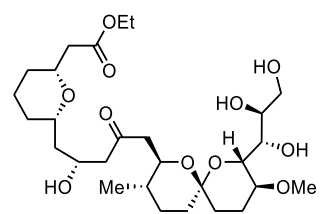

Compound $38-{ }^{1} \mathrm{H} \mathrm{NMR}\left(500 \mathrm{MHz}, \mathrm{CDCl}_{3}\right)$

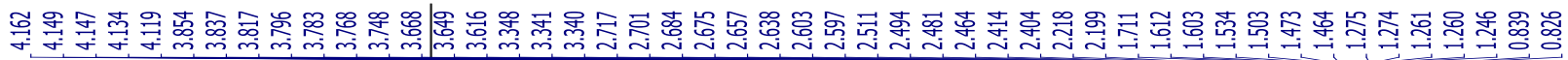
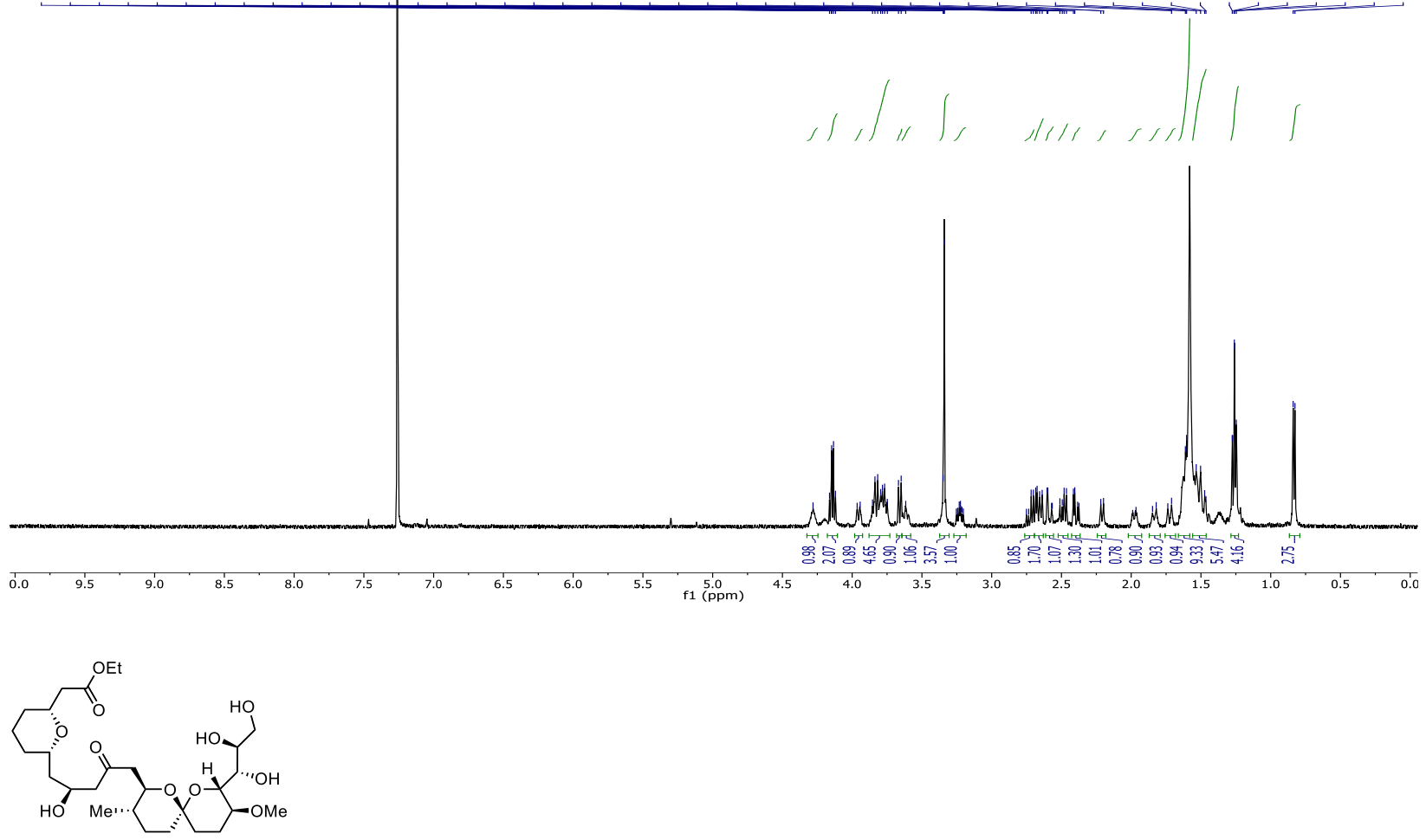

Compound $39-{ }^{1} \mathrm{H} \mathrm{NMR}\left(500 \mathrm{MHz}, \mathrm{CDCl}_{3}\right)$

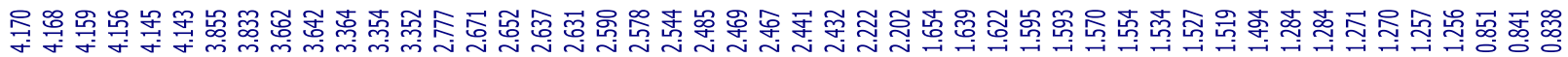

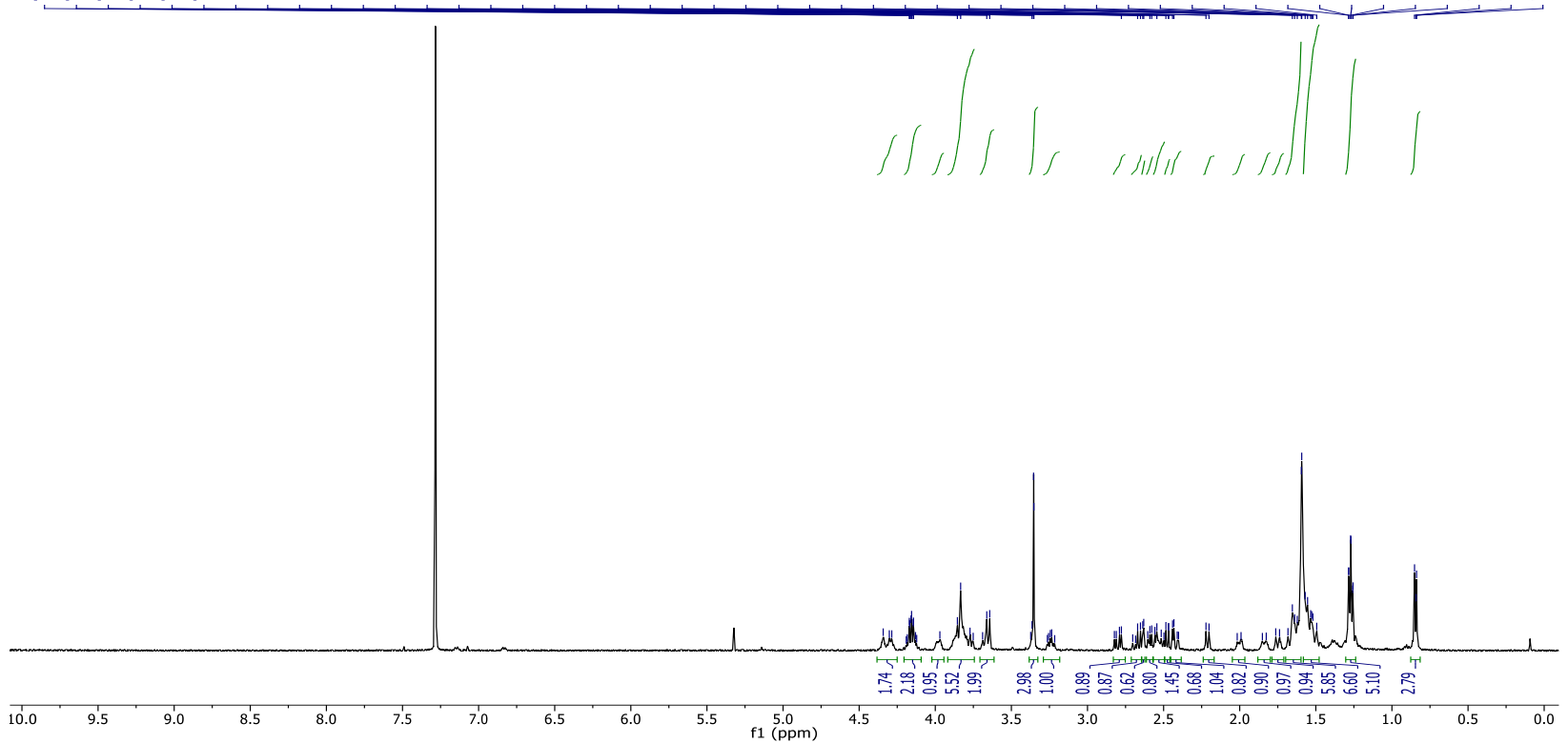


Compound 39 - HSQC (400 MHz, $\mathrm{CDCl}_{3}$ )

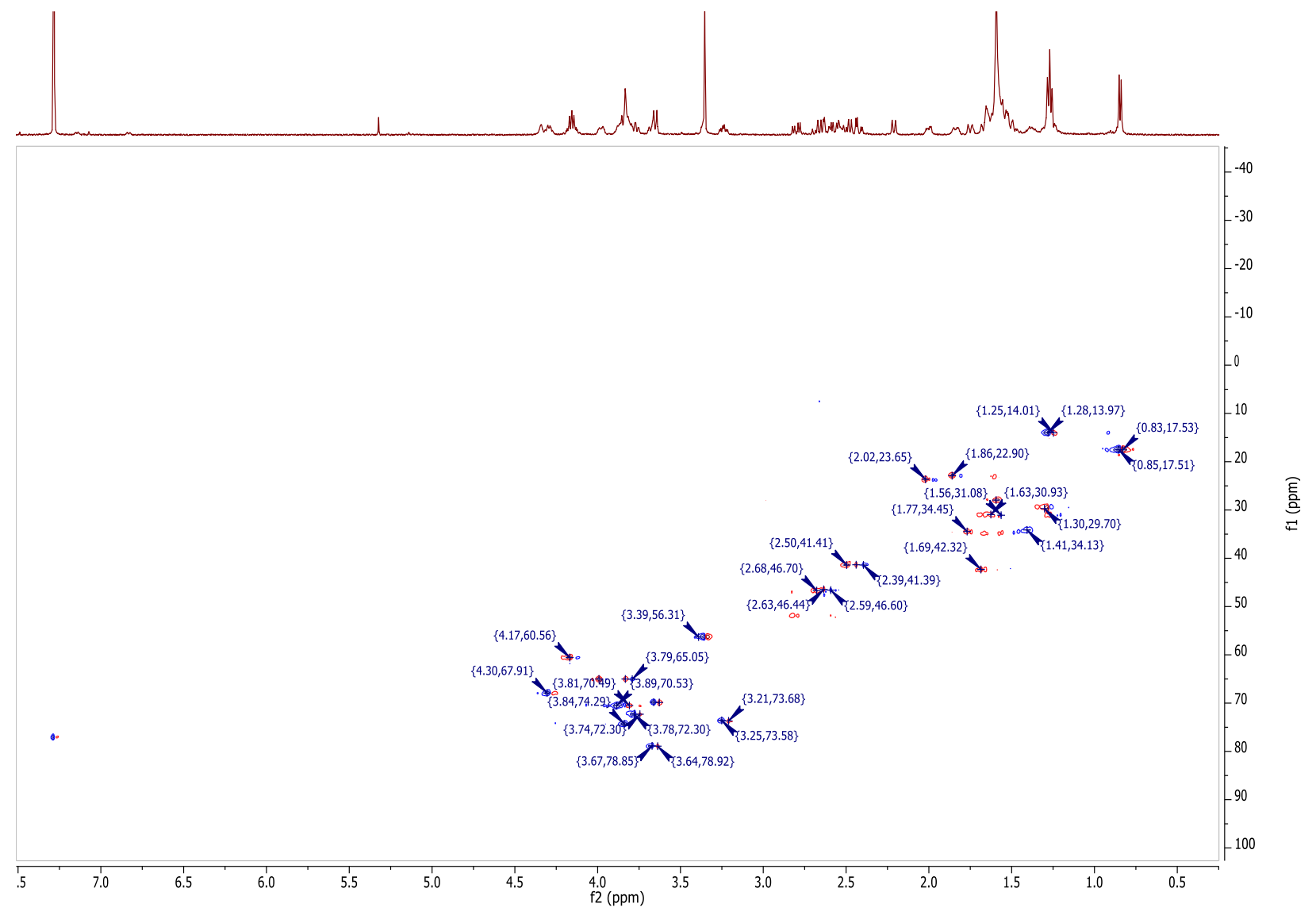




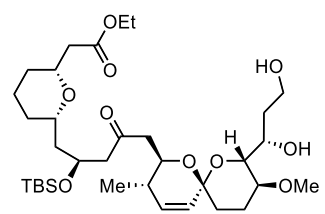

Compound $40-{ }^{1} \mathrm{H}$ NMR $\left(600 \mathrm{MHz}, \mathrm{CDCl}_{3}\right)$

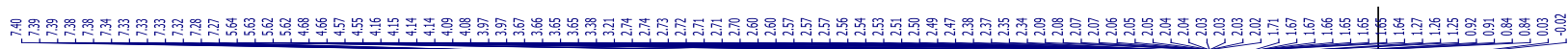
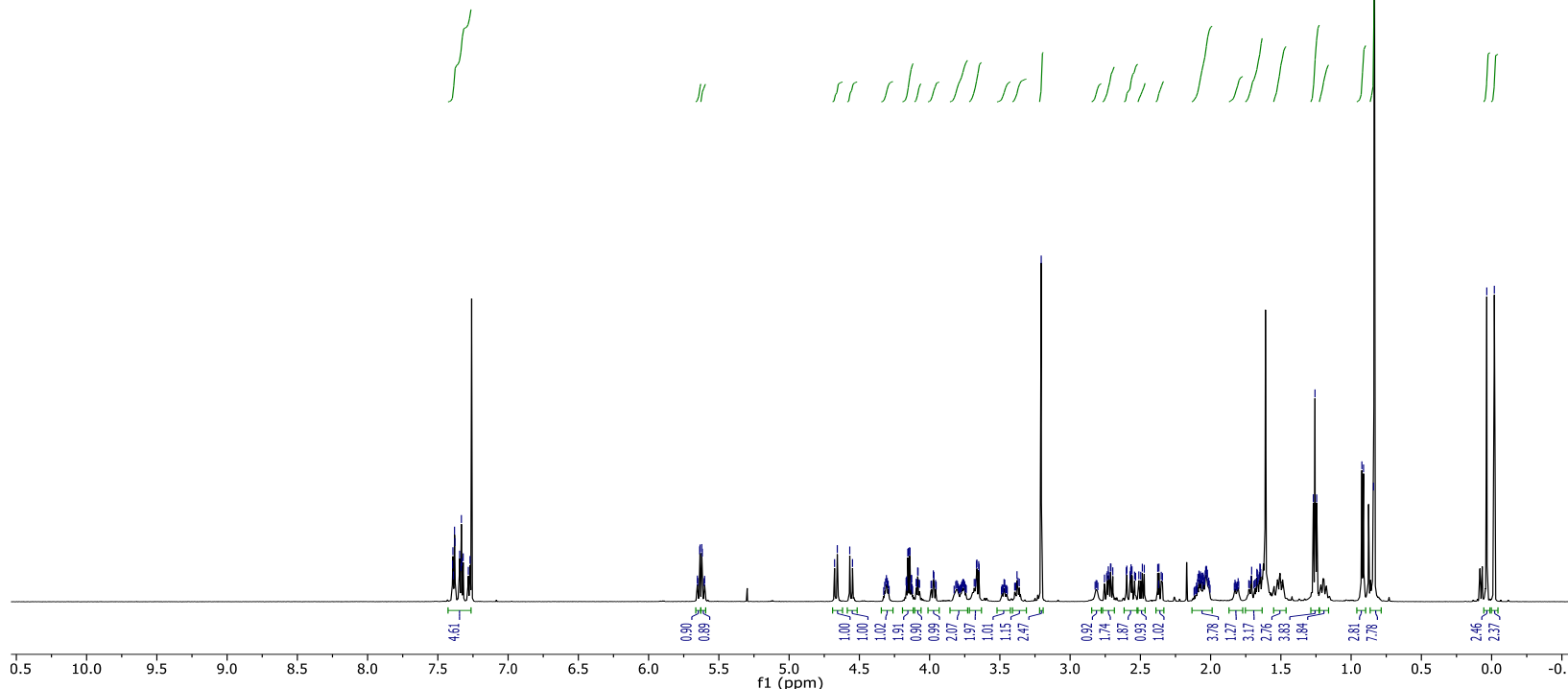

Compound $40-{ }^{13} \mathrm{C}$ NMR $\left(150 \mathrm{MHz}, \mathrm{CDCl}_{3}\right)$

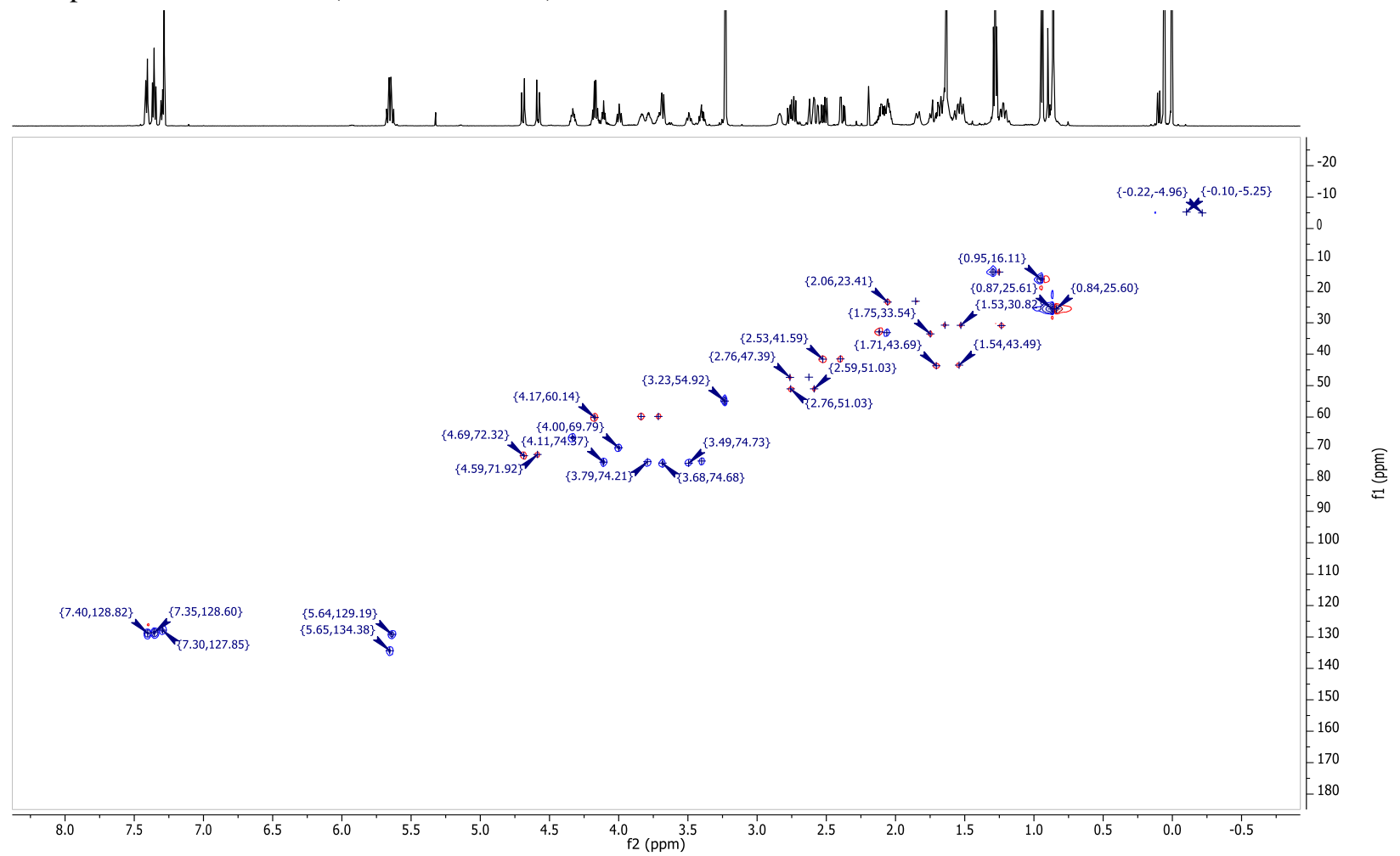




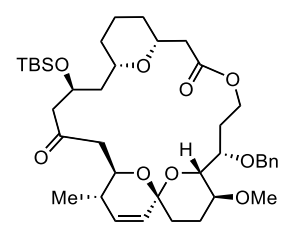

Compound 41 (Step 1) - ${ }^{1} \mathrm{H}$ NMR (600 MHz, $\mathrm{CDCl}_{3}$ )

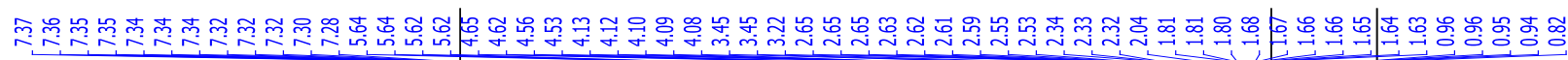

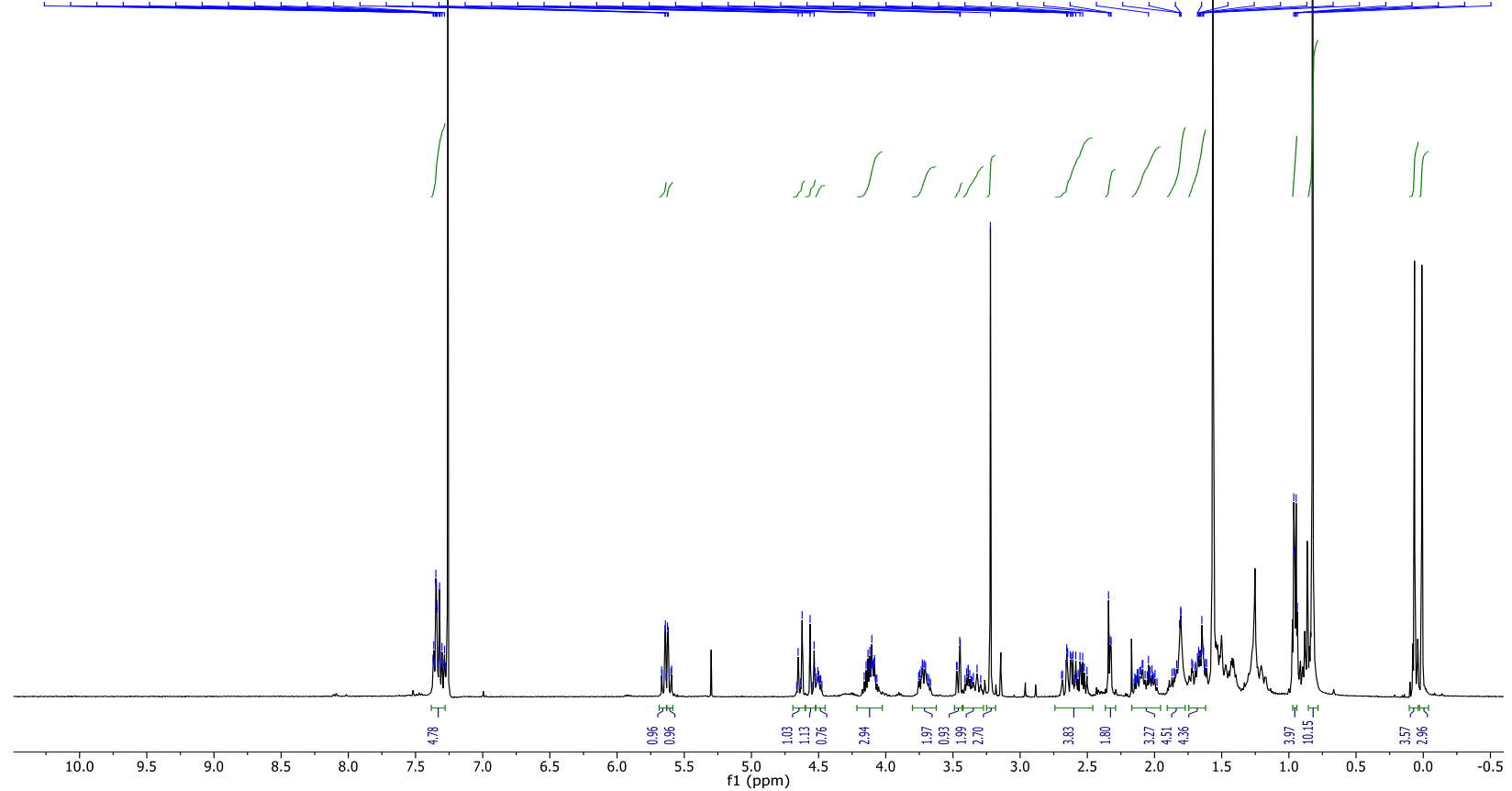

Compound 41 (Step 1) $-{ }^{13} \mathrm{C}$ NMR $\left(150 \mathrm{MHz}, \mathrm{CDCl}_{3}\right)$

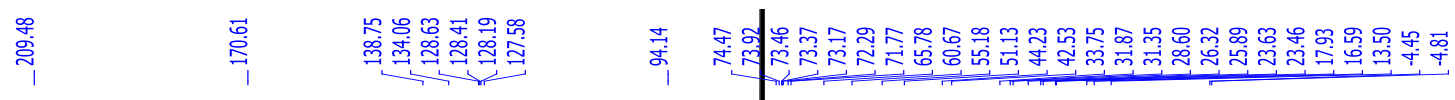

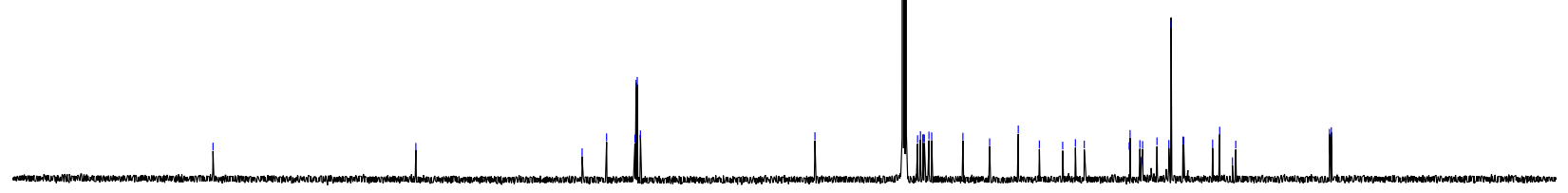

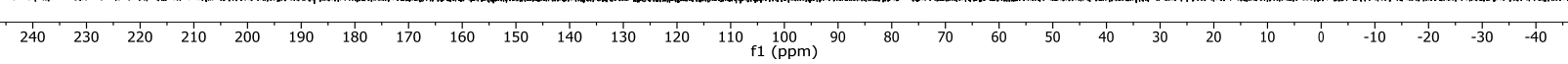



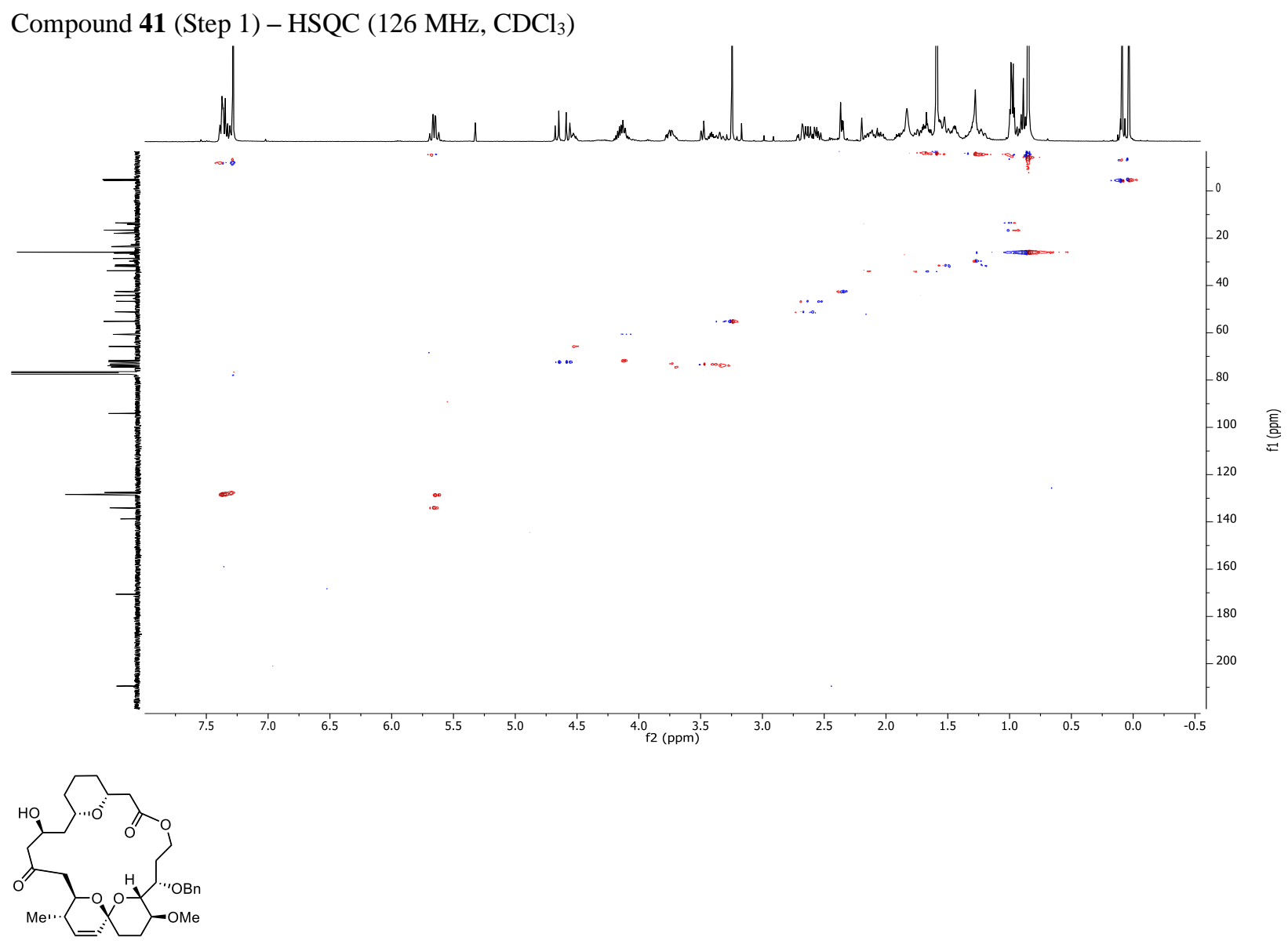

Compound $41-{ }^{1} \mathrm{H}$ NMR $\left(600 \mathrm{MHz}, \mathrm{CDCl}_{3}\right)$

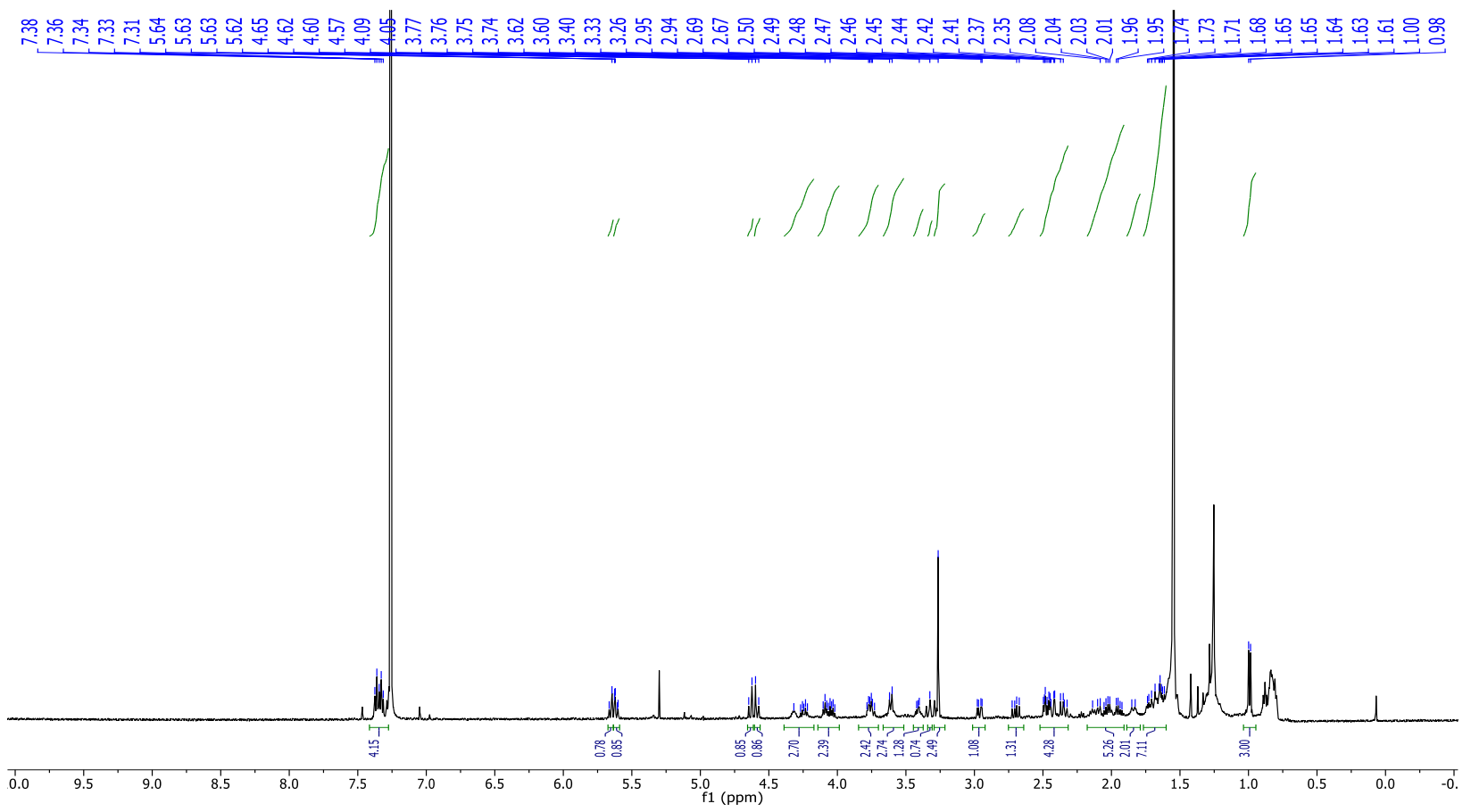

S31 


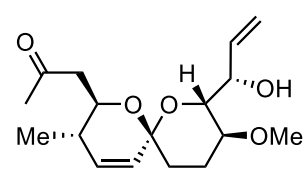

Compound $42-{ }^{1} \mathrm{H}$ NMR (400 MHz, $\mathrm{CDCl}_{3}$ )

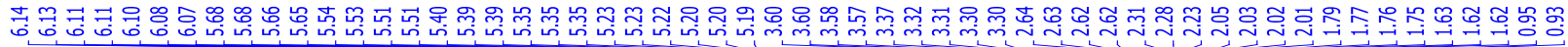

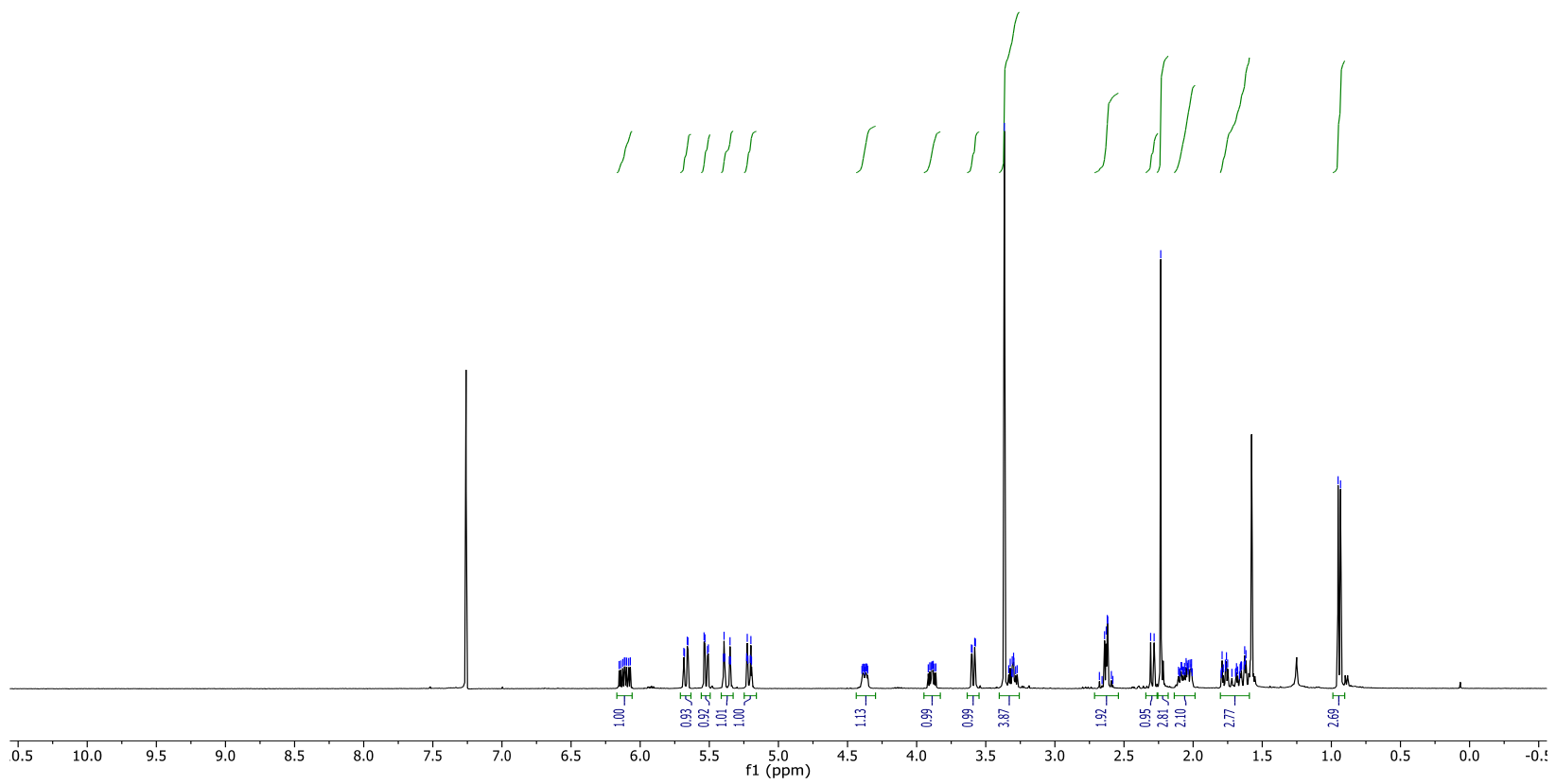

Compound 42 - HSQC (100 MHz, $\left.\mathrm{CDCl}_{3}\right)$

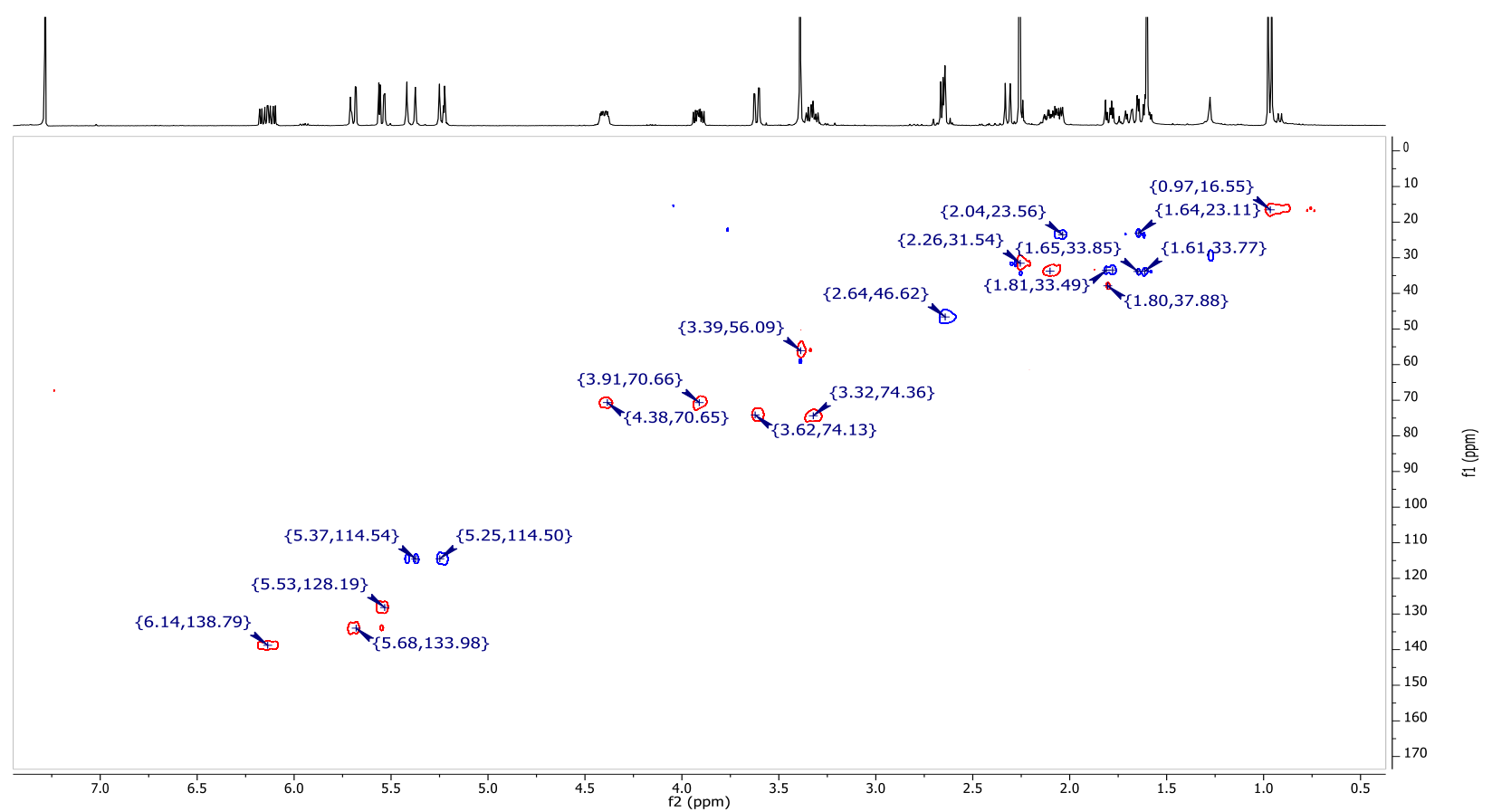




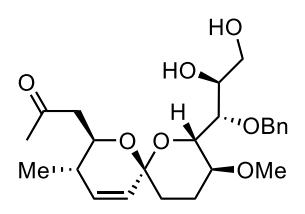

Compound $43-{ }^{1} \mathrm{H}$ NMR $\left(600 \mathrm{MHz}, \mathrm{CDCl}_{3}\right)$

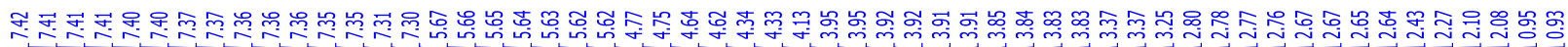

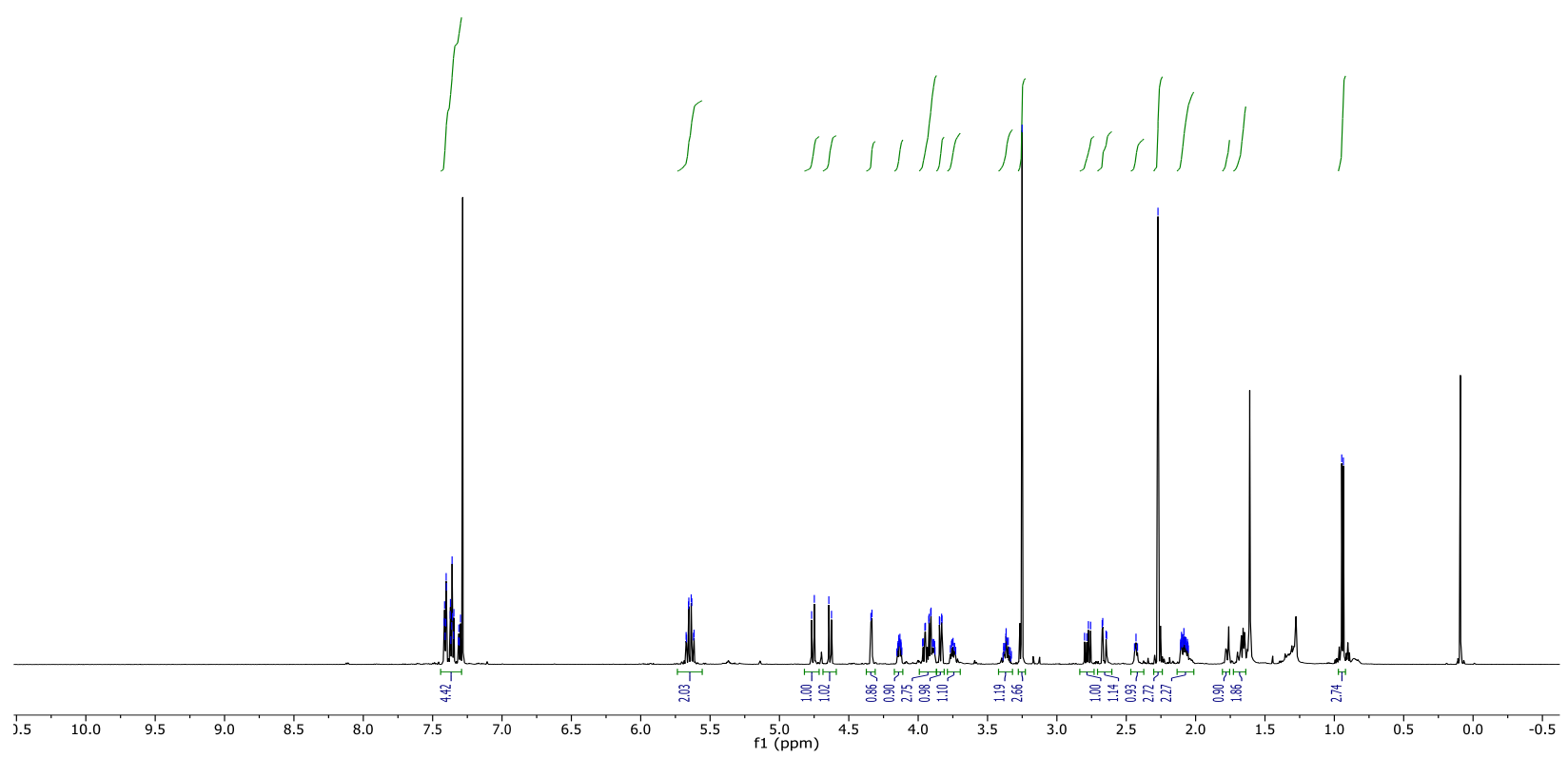

Compound 43 - HSQC (150 MHz, $\left.\mathrm{CDCl}_{3}\right)$

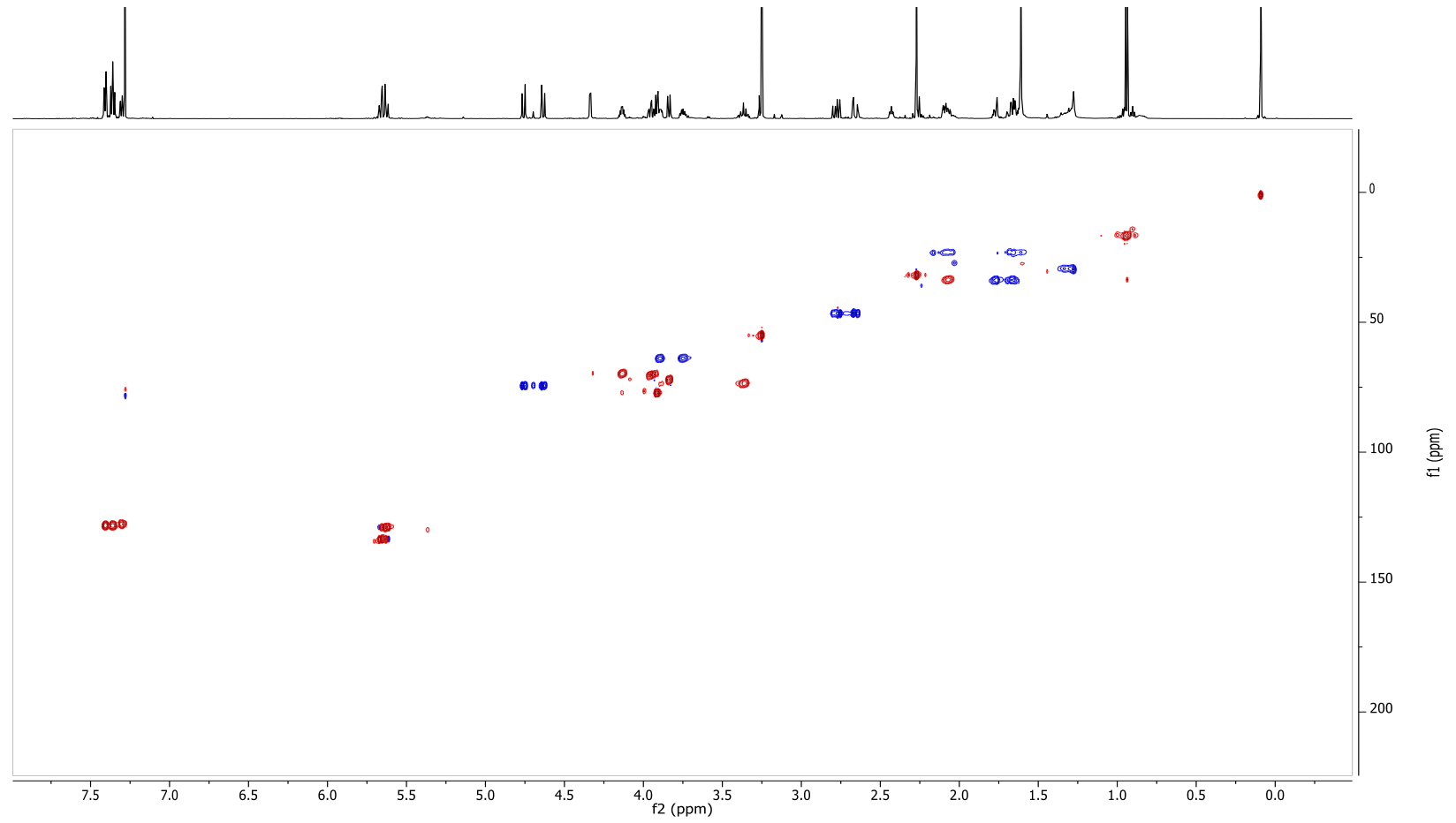


Table S1. Enzyme assay studies on analogues of southern hemisphere of spirastrellolide A (raw data concentration vs PP2A enzyme activity):

\begin{tabular}{|c|c|c|c|c|c|c|c|c|c|}
\hline Conc (M) & $\mathbf{3}$ & $\mathbf{3 5}$ & $\mathbf{3 7}$ & $\mathbf{3 8}$ & $\mathbf{3 9}$ & $\mathbf{4 1}$ & $\mathbf{5}$ & $\mathbf{4 2}$ & $\mathbf{4 3}$ \\
\hline $3.00 \mathrm{E}-04$ & 78.46 & 71.82 & 76.61 & 106.12 & 91.47 & 84.63 & 79.72 & 89.19 & 84.57 \\
\hline $1.00 \mathrm{E}-04$ & 89.40 & 77.98 & 87.53 & 110.47 & 98.76 & 83.79 & 90.54 & 89.64 & 83.52 \\
\hline $3.33 \mathrm{E}-05$ & 96.76 & 82.33 & 91.17 & 110.05 & 96.94 & 82.57 & 95.94 & 93.11 & 83.39 \\
\hline $1.11 \mathrm{E}-05$ & 108.05 & 86.11 & 95.43 & 108.71 & 98.57 & 86.34 & 100.27 & 95.89 & 90.88 \\
\hline $3.70 \mathrm{E}-06$ & 108.44 & 94.82 & 96.28 & 109.33 & 99.50 & 96.64 & 100.50 & 100.87 & 98.43 \\
\hline $0.00 \mathrm{E}+00$ & 108.50 & 96.86 & 97.77 & 103.08 & 102.09 & 97.96 & 101.36 & 96.23 & 96.49 \\
\hline
\end{tabular}

Table S2. Reference compound - cantharidic acid

\begin{tabular}{|c|c|}
\hline Conc (M) & Cantharidic Acid \\
\hline $1.00 \mathrm{E}-05$ & 1.87 \\
\hline $3.33 \mathrm{E}-06$ & 3.93 \\
\hline $1.11 \mathrm{E}-06$ & 7.45 \\
\hline $3.70 \mathrm{E}-07$ & 15.18 \\
\hline $1.23 \mathrm{E}-07$ & 36.24 \\
\hline $4.12 \mathrm{E}-08$ & 60.56 \\
\hline $1.37 \mathrm{E}-08$ & 81.38 \\
\hline $4.57 \mathrm{E}-09$ & 88.92 \\
\hline $1.52 \mathrm{E}-09$ & 90.74 \\
\hline $5.08 \mathrm{E}-10$ & 92.86 \\
\hline DMSO & 99.33 \\
\hline
\end{tabular}

Figure S3. Cantharidic acid - PP2A inhibition

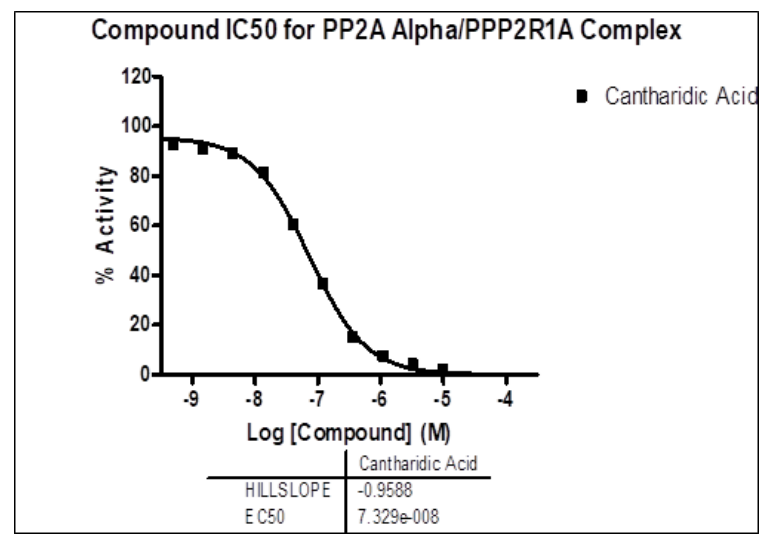

